\title{
Hydraulic behaviour of a representative structural volume for containment buildings
}

\author{
Ludovic Jason $^{\mathrm{a}, *}$, Gilles Pijaudier-Cabot ${ }^{\mathrm{b}}$, Shahrokh Ghavamian ${ }^{\mathrm{c}}$, Antonio Huerta ${ }^{\mathrm{d}}$ \\ ${ }^{\text {a } C E A ~ S a c l a y, ~ D M 2 S / S E M T / L M 2 S, ~ B a t .607, ~} 91191$ Gif sur Yvette, France \\ ${ }^{\mathrm{b}} R \& D 0$, GeM, Institut de Recherche en Génie Civil et Mécanique Ecole Centrale de Nantes, Université de Nantes, \\ CNRS 1, rue de la Noé, BP 92101, F44300 Nantes, France \\ ${ }^{\mathrm{c}}$ EDF R\&D, 1 avenue du Général de Gaulle, 92141 Clamart Cedex, France \\ d Laboratori de Càlcul Numèric, Departament de Matemàtica Aplicada III Universitat Politècnica de Catalunya, \\ Jordi Girona 1-3, E-08034 Barcelona, Spain
}

\begin{abstract}
For particular structures like containment buildings of nuclear power plants, the study of the hydraulic behaviour is of great concern. These structures are indeed the third barrier used to protect the environment in case of accidents. The evolution of the leaking rate through the porous medium is closely related to the changes in the permeability during the ageing process of the structure. It is thus essential to know the relation between concrete degradation and the transfer property when the consequences of a mechanical loading on the hydraulic behaviour have to be evaluated. A chained approach is designed for this purpose. The mechanical behaviour is described by an elastic plastic damage formulation, where damage is responsible for the softening evolution while plasticity accounts for the development of irreversible strains. The drying process is evaluated according to a non-linear equation of diffusion. From the knowledge of the damage and the degree of saturation, a relation is proposed to calculate the permeability of concrete. Finally, the non-homogeneous distribution of the hydraulic conductivity is included in the hydraulic problem which is in fact the association of the mass balance equation for gas phase and Darcy law. From this methodology, it is shown how an indicator for the hydraulic flows can be deduced.
\end{abstract}

\section{Introduction}

In high power French nuclear power plants (1300 and $1400 \mathrm{MWe})$, the internal confinement vessel represents the third passive barrier for the environmental protection in case of accidents. Considering that there is no liner, concrete has to provide the air tightness. These structures are carefully monitored. Integrity tests are regularly (every 10 years) performed to check the effective ability of the containment building to prevent leakage. They consist in a dry air pressure applied inside the internal vessel and a measurement of the leaking rate which cannot be above a given threshold defined by regulation instances. These measurements provide a rather global piece of information about the structural behavior only.

\footnotetext{
* Corresponding author.

E-mail address: Ludovic.Jason@ cea.fr (L. Jason).
}

Experimental investigation on the inner concrete confinement vessel such as core testing is not easily feasible for obvious reasons involving security. It is difficult to know beforehand the distribution of the leakage rate over the vessel, from which preventive action can be planned during the maintenance process. On top, further evolution of the vessel serviceability cannot be predicted and long term maintenance strategies may rely on statistical extrapolations and rather arbitrary simplifying assumptions related, for instance to the distribution and opening of cracks over the vessel upon the application of the internal pressure. Therefore, there is a need for developing numerical models aimed at describing the mechanical response of containment vessels, the evolution of the transfer properties of the material upon damage and cracking that may occur, and finally the distribution of leakage over the structure during integrity tests. This is the purpose of this contribution which is aimed at presenting a simplified computational strategy for modelling integrity tests and computing leaking rates and their distribution 
over a structural element that is representative of reinforced and pre-stressed massive concrete vessels.

Devising a computational model for the simulation of the integrity test on containment vessels is a problem for which major difficulties have to be addressed. Among them, the first one deals with the constitutive model for concrete since it is important to describe the mechanical response of the material and the inherent variations of the transfer properties of the material. Concrete is a porous multiphase material where the amount of micro-cracking due to mechanical loads, temperature, and moisture content (saturation degree) have a great influence on the material permeability which governs leakage. The second difficulty is related to the computational model to be implemented. Concrete vessels are large massive tridimensionnal structures that are heavily reinforced and pre-stressed. Capturing the mechanical degradation of the material, in the simplified pure mechanical problem for instance, requires a finite element description that is extremely refined. Classically, finite element models for failure analyses rely on enriched continuum strain softening models which contain an internal length of the order of the size of the aggregate in concrete (see e.g. the review by Bazant and Jirasek, 2002). The finite element size ought to be smaller than this internal length for an accurate description of material failure. The corresponding finite element model (3D) of an entire vessel is very large, with several millions of degree of freedom. The third difficulty is related to the solution scheme that is to be implemented in order to solve this complex coupled problem. Several authors have proposed coupled approaches to quar response of concrete. In the formulation is consti corresponding to water nal energy balance and $m$ completed by the set of present a mathematical model for the analysis of hygro-thermal is extremely delicate, far beyond the reach of current engineering practice. Solving simultaneously this coupled problem increases dramatically the number of unknowns, with strongly non-linear governing equations. Considering that the mechanical non-linear problem of a complete vessel is still a challenge, the entire coupled problem seems far out of reach and there is still room for devising simplified models. These simplified models may appear less realistic from a theoretical point of view, they have the advantage, however, to provide at least qualitative information from which maintenance decisions can be made.

In this paper, a chained approach to the computation of leakage of vessels during integrity tests is presented. The targeted problem is the hydraulic one, where the leaking rates are evaluated from the resolution of a classical hydraulic problem and thus relying on the knowledge of the permeability of concrete and moisture content. The distribution of permeability depends on the amount of moisture and micro-cracking in the material. It is obtained in two independent steps: the calculation of the saturation degree of concrete throughout the structure and the distribution of damage, solution of a pure mechanical problem. Hence the hydraulic, mechanical and drying calculations are uncoupled.

The paper is divided in three parts. In the first one, the hydraulic problem and the general methodology are outlined. The constitutive equations for the mechanical and drying problems are recalled in the second section, along with the influence of these two phenomena on the material permeability. Finally, the proposed chained computational strategy is illustrated on a 2. Problem descyiption

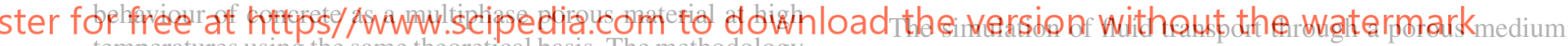

temperatures using the same theoretical basis. The methodology is applied on two-dimensional problems to highlight the particular effect of temperature on concrete. Wang and Cheng (1996) or Al Najim et al. (2003) study similar problems and propose one-dimensional applications only. Mainguy et al. (2001) use the same theoretical basis and apply it to drying tests of weakly permeable cement-based materials with a model involving dry-air and water-vapor components in gas phase and pure liquid water phase (the mechanical part is not taken into account). Again, one-dimensional applications are considered for which the evolution of the saturation degree and total gas pressure distribution are studied.

These theories provide comprehensive results and help at the understanding of interaction between thermal, hydraulic and mechanical phenomena. Aside from the difficulties that are involved in the determination of the model parameters entering in the computational model, some of them being easily accessible (Young's modulus, dynamic viscosity of fluids, etc.) and some of them being more difficult to evaluate (dilation coefficients of porous materials, mass heat of grains, etc.), their implementation in the context of the $3 \mathrm{D}$ analysis of vessels is based on the resolution of three mass balance equations for fluid, gas and vapor (Bear, 1991 or Mainguy et al., 2001):

$$
\begin{aligned}
& \frac{\partial}{\partial t}\left(\phi \rho_{1} S_{1}\right)=-\nabla \cdot\left(\phi S_{1} \rho_{1} v_{1}\right)-\mu_{1 \rightarrow \mathrm{v}} \\
& \frac{\partial}{\partial t}\left(\phi \rho_{\mathrm{v}}\left(1-S_{1}\right)\right)=-\nabla \cdot\left(\phi\left(1-S_{1}\right) \rho_{\mathrm{v}} v_{\mathrm{v}}\right)+\mu_{1 \rightarrow \mathrm{v}} \\
& \frac{\partial}{\partial t}\left(\phi \rho_{\mathrm{a}}\left(1-S_{1}\right)\right)=-\nabla \cdot\left(\phi\left(1-S_{1}\right) \rho_{\mathrm{a}} v_{\mathrm{a}}\right)
\end{aligned}
$$

with $\phi$ the material total porosity and $S_{1}$ the degree of saturation

$$
S_{1}=\frac{V_{\mathrm{W}}}{V_{\mathrm{V}}}=\frac{C}{C_{\mathrm{sat}}}
$$

where $V_{\mathrm{W}}$ and $V_{\mathrm{V}}$ are respectively the volumes of liquid water and free space. $C$ is the volumetric water content and $C_{\text {sat }}$ the water content for water saturated sample. $\rho_{\mathrm{l}}, \rho_{\mathrm{v}}, \rho_{\mathrm{a}}$ and $v_{\mathrm{l}}, v_{\mathrm{v}}, v_{\mathrm{a}}$ are the mass densities and velocities for liquid, vapor and dry air respectively. $\mu_{1 \rightarrow \mathrm{v}}$ denotes the rate of liquid-water mass changing into vapor per unit of volume. 
Assuming that the gaseous phase does not contain vapor and considering the gas transport only, the associated mass balance equation can be rewritten:

$\frac{\partial}{\partial t}\left(\phi \rho_{\mathrm{g}}\left(1-S_{\mathrm{l}}\right)\right)=-\nabla \cdot\left(\phi\left(1-S_{\mathrm{l}}\right) \rho_{\mathrm{g}} v_{\mathrm{g}}\right)$

The gas velocity is expressed as a function of the gas pressure $P_{\mathrm{g}}$ using Darcy law:

$\phi\left(1-S_{1}\right) v_{\mathrm{g}}=-\frac{K_{\mathrm{g}}}{\eta_{\mathrm{g}}} \nabla\left(P_{\mathrm{g}}\right)$

where $K_{\mathrm{g}}$ is the gas permeability and $\eta_{\mathrm{g}}$ the associated dynamic viscosity. These equations fit to the case of integrity tests of containment facilities where dry air pressure is applied inside the concrete vessel. Darcy's law is applicable in the context of a continuum analysis, i.e. assuming that the vessel does not contain major through cracks. Moreover, no interaction between the air and the liquid phases is assumed.

Considering the gas as "ideal", the volumetric gas mass can be written as a function of the gas pressure:

$\frac{P_{\mathrm{g}}}{\rho_{\mathrm{g}}}=\frac{R T}{M}$

where $M, R$ and $T$ respectively stand for the molar mass of gas, ideal gas constant and temperature. Finally, combining Eqs. (3)-(5), the hydraulic problem is driven by the equation:
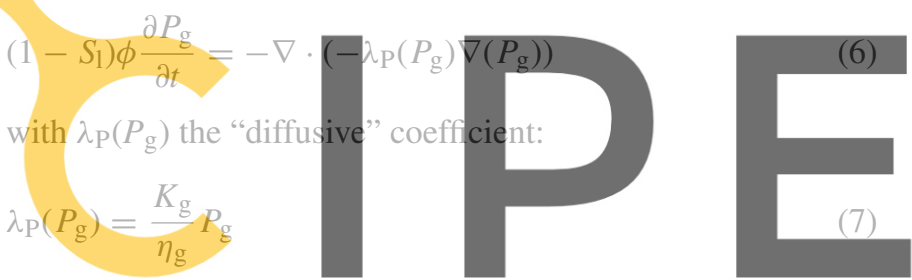

From this equation, it is clear that the study of the gas transfer

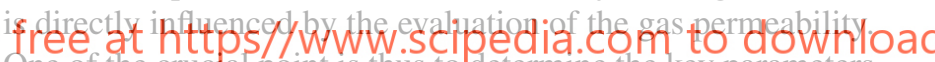
One of the cructalpoint is thus to determine the key parameters that influence the value of the hydraulic conductivity.

\subsection{Evaluation of the permeability}

The parameters that influence the evolution of gas permeability have been identified by several authors. In Villain et al. (2001), Picandet et al. (2001) or Sugiyama et al. (1996a,b) for example, the permeability is measured experimentally for different values of the degree of saturation. As shown in Fig. 1, the drier the concrete is, the greater the value of the gas hydraulic conductivity becomes. The evolution of the degree of saturation through the life time of the structure, that is to say the time of drying, is thus a key point for the evaluation of the permeability. Sugiyama et al. (1996a) quantified the influence of a mechanical loading on the value of the transfer property. In Fig. 2, a stress threshold is highlighted from which the hydraulic conductivity increases significantly.

These two parameters (saturation and mechanical loads) will be considered here to drive the variation of permeability. Another possibility would have probably been to add chemical effects

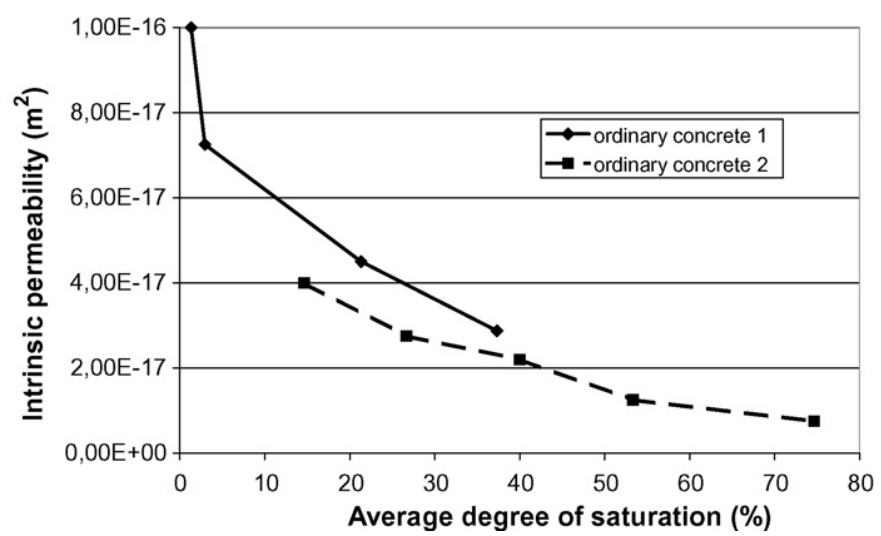

Fig. 1. Evolution of the permeability as a function of the average saturation degree for two ordinary concrete (from Villain et al., 2001).

(carbonation for example, see Basheer et al., 2001) but the internal containment building is protected from outside attacks. Thus, carbonation or leaching are not relevant, although they may be for other types of structures such as waste containment vessels or dams.

For the sake of simplicity, the decomposition proposed by Baroghel-Bouny et al. (1999), among others, is used. The total gas permeability $K_{\mathrm{g}}$ is split into two terms:

$K_{\mathrm{g}}=k_{\mathrm{rg}}\left(S_{1}\right) K(\mathrm{~ms}), \quad$ with $0 \leq k_{\mathrm{rg}} \leq 1, \quad k_{\mathrm{rg}}=0$ if $S_{1}=1$,

$k_{\mathrm{rg}}=1$ if $S_{1}=0$

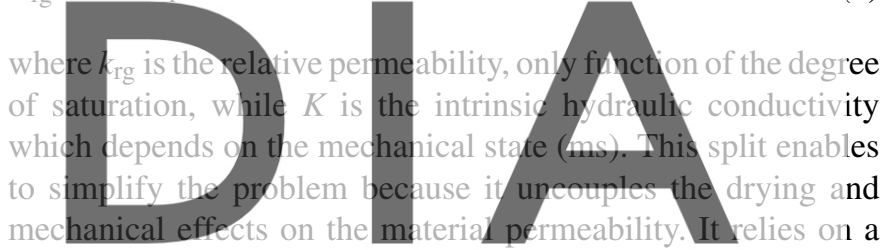
relationship between the factor $k_{\mathrm{rg}}$ and the saturation degree $S_{1}$ and another one between the permeability and the mechanical state, y.ersign withouthe the waternarir in Section 3 of this paper, but prior to that, we may now devise the simplified methodology for computing leaking rates according to the above equations governing the hydraulic problem.

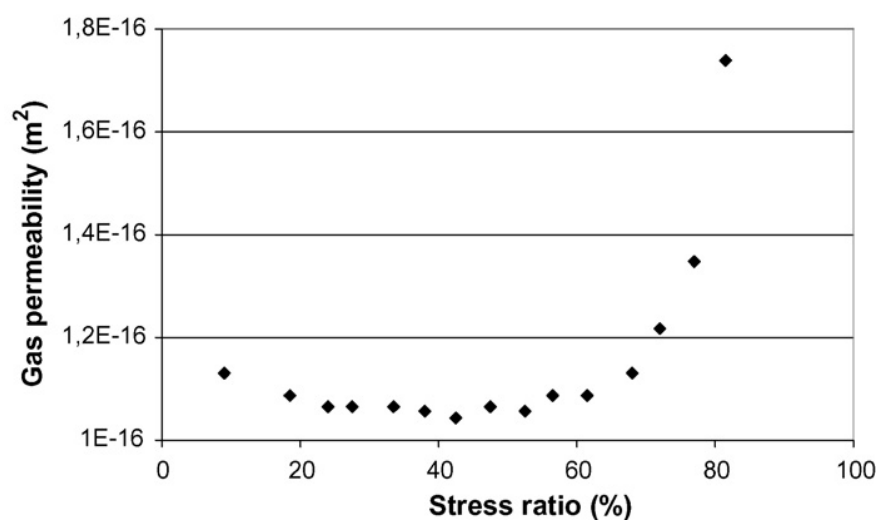

Fig. 2. Evolution of the permeability as a function of the mechanical stress ratio (ratio between the applied stress and the peak stress), from Sugiyama et al. (1996a). 


\subsection{General methodology_chained calculation process}

Three processes are taken into account for the study of the hydraulic behaviour: the evolution of the mechanical state (damage), the drying effect (evolution of the degree of saturation) and the gas internal pressure (hydraulic loading). A chained method is applied, the global process is illustrated in Fig. 3.

The mechanical state is assumed to be defined independently from drying and vice versa. The first one (mechanical) serves for the computation of the material permeability $K$ in Eq. (8) and the drying calculation serves for the calculation of the material permeability $k_{\mathrm{rg}}$ as a function of the saturation degree in the same equation, and in Eq. (6) of the hydraulic problem. These quantities are defined locally, point-wise at integration points in a finite element computation. The distribution of gas permeability and saturation degree are then incorporated into the governing equation (6) of the hydraulic problem.

This choice of a chained approach compared to the resolution of a fully coupled set of equations implies several assumptions. First of all, it is important to observe from Figs. 1 and 2 that small variations of the mechanical state or of the degree of saturation may yield large variations of permeability (several orders of magnitude). Conversely, the integrity test is conducted on such a short period of time $(48 \mathrm{~h})$ that it is assumed that gas flow will have a very limited influence on the moisture content (drying occurs during over a period of time of 10-20 years at least). The applied internal pressure is not expected to yield
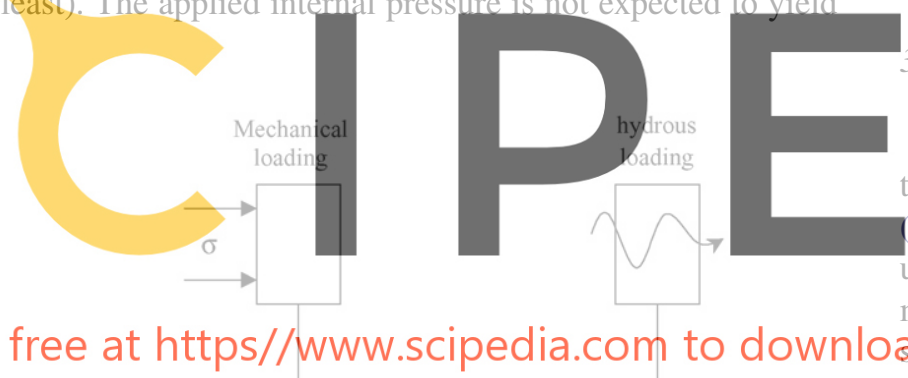

\section{Drying and mechanical computations}

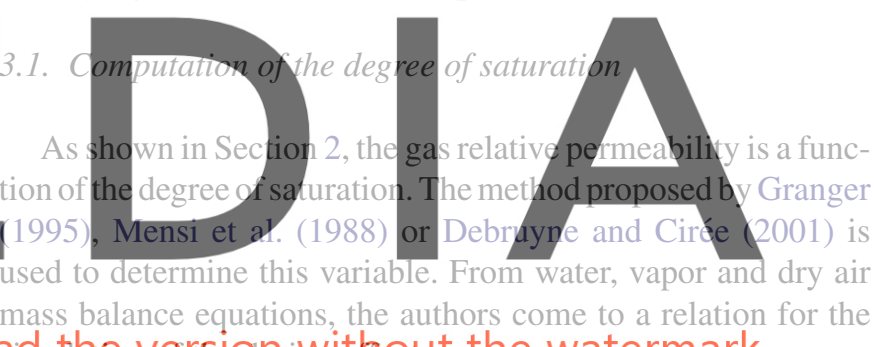

hydraulic fracture, thus the hydraulic problem may be considered as uncoupled from the drying and mechanical ones in a first approximation.

In this chained approach, the drying process is assumed to be independent from the mechanical state of concrete. Both occur separately, drying evolves with time and it is computed prior to each integrity test for which a mechanical calculation is performed (Fig. 3, bottom). In other words, the saturation degree is assumed to have a negligible influence on the cracking process and vice versa. Experimental evidences and theoretical models for coupled damage-drying problems exist in the literature (see e.g. Yurtdas et al., 2004). We consider, however, that damage during the service life (drying time) of the vessel is moderate. Furthermore, micro-cracks may open during integrity tests, but because of the pre-stressing, they might close, limiting the preferential intrusion of moisture. Hence the mechanical state may have a moderate influence on the distribution of moisture within the vessel thickness. Conversely, the distribution of moisture has an influence on the mechanical properties. Following the same technique as for the permeability, i.e. by indexing the mechanical properties on the saturation degree, this could be incorporated in our approach. It should be the subject of future developments, following the same spirit as the method employed in this paper for the update of the material permeability over the service life of the vessel.
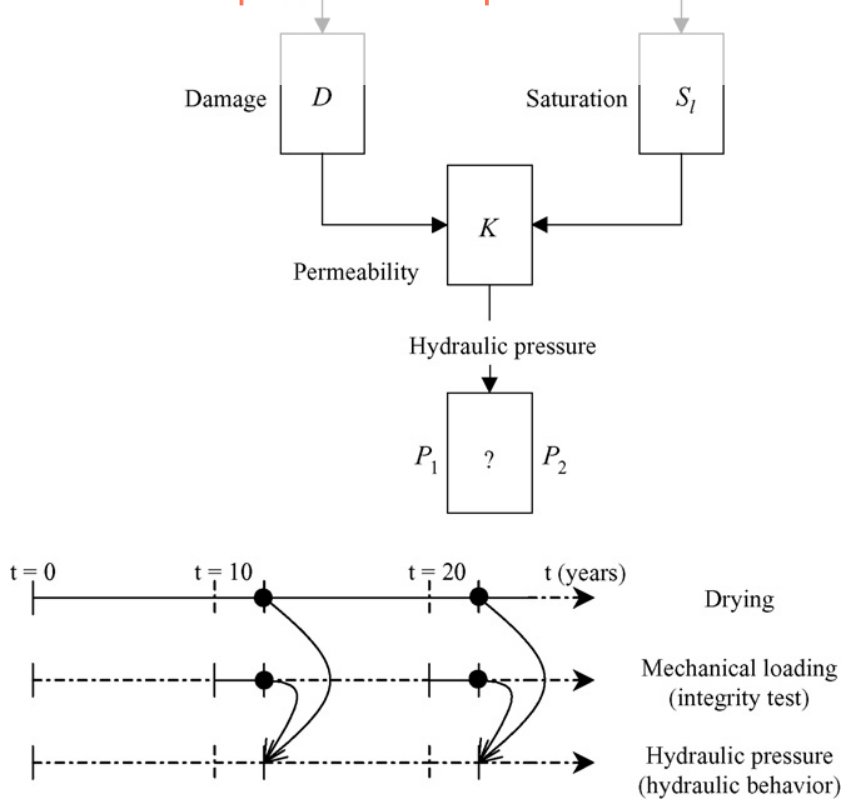

$\frac{\partial C^{\mathrm{fl}}}{\partial t}=\nabla \cdot\left[\lambda_{\mathrm{c}}\left(C^{\mathrm{fl}}, T\right) \nabla\left(C^{\mathrm{fl}}\right)\right]$

with $C^{\mathrm{fl}}$ the volumetric water content and $\lambda_{\mathrm{c}}\left(C^{\mathrm{fl}}, T\right)$ the nonlinear diffusive coefficient function of $C^{\mathrm{fl}}$ and temperature $T$. The temperature distribution is defined from a preliminary computation based on the resolution of a linear equation:

$\rho C_{\mathrm{p}} \frac{\partial T}{\partial t}+\nabla \cdot\left[-\lambda_{\mathrm{T}} \nabla(T)\right]=0$

with $\rho C_{\mathrm{p}}$ the volumetric heat at a constant pressure and $\lambda_{\mathrm{T}}$ the constant thermal conductivity.

For the expression of $\lambda_{\mathrm{c}}\left(C^{\mathrm{fl}}, T\right)$, the following relation has been chosen (Granger, 1995):

$\lambda_{\mathrm{c}}\left(C^{\mathrm{fl}}, T\right)=A \exp \left(B C^{\mathrm{fl}}\right) \frac{T}{T_{0}} \exp \left(-\frac{Q_{i}}{R}\left(\frac{1}{T}-\frac{1}{T_{0}}\right)\right)$

with $A, B, T_{0}$ and $Q_{i} / R$ four model parameters. Once the distribution of the volumetric water content is evaluated, the degree 
of saturation is deduced:

$S_{1}=\frac{C^{\mathrm{fl}}}{C_{\mathrm{sat}}}$

At the end of the computation, the value of the degree of saturation is obtained at each point and during the life time of the structure.

\subsection{Influence of the degree of saturation on the permeability}

Different studies have been reported, which underline the influence of the water saturation on the hydraulic conductivity. For example, Abbas et al. (1999) and Villain et al. (2001) define some experimental relations between $K_{\mathrm{g}}$ and $S_{1}$. Nevertheless, these laws are strongly related to the composition of concrete. That is why they have not been chosen in our approach.

Grasberger and Meschke (2000), Baroghel-Bouny et al. (1999) or Mainguy et al. (2001) use the theory described by Van Genuchten (1980) to quantify the evolution of the relative permeability as a function of the saturation. In this approach, based on statistical considerations, $k_{\mathrm{rg}}$ is written as

\section{$k_{\mathrm{rg}}=\left(1-S_{1}\right)^{\mathrm{q}}\left(1-S_{1}^{1 / \mathrm{m}}\right)^{2 \mathrm{~m}}$}

where $q$ and $m$ are two parameters. $m$ is calibrated from the capillary pressure curve $P_{\mathrm{g}}-P_{1}=f\left(S_{1}\right)$ with $P_{1}$ the liquid pressure. A value of $m=0.5$ has been chosen. It represents an appropriate averige considering the parameters given by Monlouis-Bonnaird et al. (2004), Mainguy et al. (2001), Baroghel-Bouny et al. (1999) and Dal Pont and Ehrlacher (2004)

For the determination of $q$, Van Genuchten (1980) proposes $q=0.5$ as an optimal value from an experimental calibration $(45$ types of soil). The relative permeability is then given by



Fig. 4. Evolution of the relative gas permeability as a function of the degree of saturation for two values of $q$.

\subsection{Mechanical problem}

There are several possibilities for selecting a constitutive relation for the mechanical response of concrete. Following the experimental and theoretical studies by Picandet et al. (2001) and Chatzigeorgiou et al. (2005), it is important that the output of the mechanical model be a measure of damage, i.e. a decrease of the material stiffness of the material upon micro-cracking. In these works it was observed that it is damage that controls the permeability of the material. Within the framework of isotropic, scalar damage models, the damage scalar $D$ is defined from the ratio between the initial elastic stiffness $E$ and the unloading Slope $E^{\prime}$, following the equation:
$D=1-\frac{E^{\prime}}{E}$
This approach, where perneability is a function of damage, has
been also implemented in the past in several computational studies (see e.g. Gawin et al., 2003; Bary et al., 2000). As shown

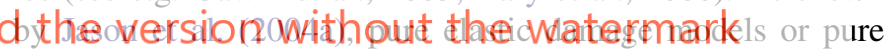
elastic plastic constitutive laws are not totally satisfactory for the purpose of evaluating the material permeability. Actually, it is essential to evaluate the evolution of the elastic stiffness

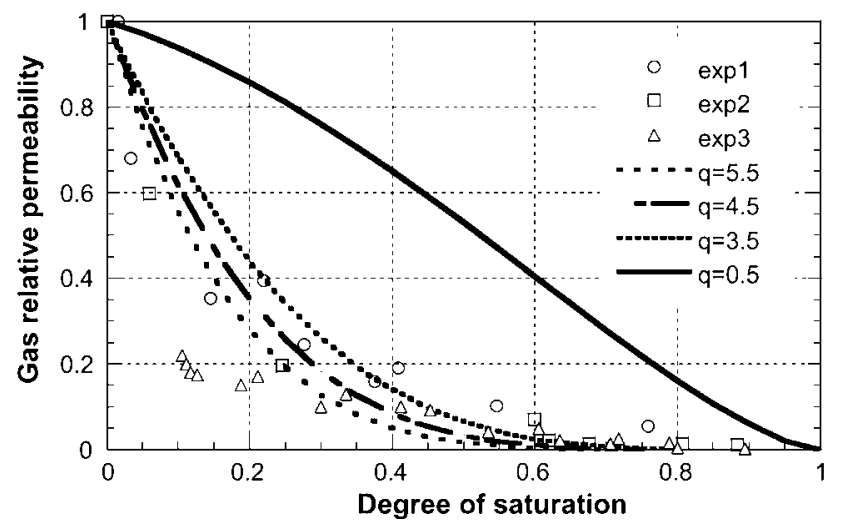

Fig. 5. Evolution of the gas relative permeability as a function of the saturation degree. Comparison between simulation and experiment. Exp1 and exp2: ordinary concrete and high performance concrete from Villain et al. (2001), exp3: ordinary concrete from Abbas et al. (1999).
$k_{\mathrm{rg}}=\left(1-S_{\mathrm{l}}\right)^{4.5}\left(1-S_{\mathrm{l}}^{2}\right)$
Fig. 4 gives the comparison between Eqs. (14) and (15). Given the significant differences between the two relations, an additional comparison analysis has been performed: Fig. 5 illustrates the evolution of the relative gas permeability as a function of et al., 2001; Abbas et al., 1999). Eqs. (14) and (15) are also plotted. The sharp decrease of $k_{\text {rg }}$ for low saturations is not captured by the initial calibration proposed by Van Genuchten (1980) $(q=0.5)$. From the experimental results on concrete, values between 3.5 and 5.5 seem to be appropriate. $q=5.5$ correctly describes the evolution of permeability for low degrees of saturation whereas $q=3.5$ seems more appropriate for $S_{1}$ between 0.3 and 0.5 . An acceptable compromise is $q=4.5$. In the following, the relative permeability will be thus written as

$$
k_{\mathrm{Ig}}=\left(1-S_{\mathrm{l}}\right)\left(1-S_{1}^{2}\right)
$$

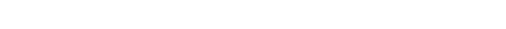


of the material as accurately as possible since it is the quantity that enters in the evolution of permeability. Elasto-plasticity and elasto-damage models fail to do so because the material response exhibits irreversible strain and a degradation of stiffness at the same time. The elasto-plastic damage model devised by Jason et al. (2006) is implemented and we recall in the following the basic equations of this constitutive model.

The total stress $\sigma$ is a function of the damage variable $D$ and of an effective stress $\sigma^{\prime}$ (stress of the undamaged material) that solves the equation of a plastic yield surface:

$\sigma=(1-D) \sigma^{\prime}$

The effective stress approach provides a simple way to separate damage and plastic processes.

The plastic process is described with the help of a yield function $F$ inspired from Etse and Willam (1984) and modified by Crouch and Tahar (2000):

$F\left(\sigma^{\prime}, k_{\mathrm{h}}\right)=\bar{\rho}^{2}\left(\sigma^{\prime}\right)-\frac{\hat{k}\left(\sigma^{\prime}, k_{\mathrm{h}}\right) \bar{\rho}_{\mathrm{c}}^{2}\left(\sigma^{\prime}\right)}{r^{2}\left(\sigma^{\prime}\right)}$

where $k_{\mathrm{h}}$ is the hardening internal variable and $\bar{\rho}, \bar{\rho}_{\mathrm{c}}, r$ and $\hat{k}$ are functions of the effective stress and internal variable.

The damage growth is controlled by the elastic strain. We use here the classical isotropic model due to Mazars (1984) which incorporates strain softening:

$D\left(\varepsilon^{\mathrm{e}}\right)=\alpha_{\mathrm{t}}\left(\varepsilon^{\mathrm{e}}\right) D_{\mathrm{t}}\left(\varepsilon^{\mathrm{e}}\right)+\alpha_{\mathrm{c}}\left(\varepsilon^{\mathrm{e}}\right) D_{\mathrm{c}}\left(\varepsilon^{\mathrm{e}}\right)$ a zero stress corresponds to a zero strain, the unloading slopes are not correct compared with the experiment and the value of damage is overestimated. On the contrary, with the elastic plastic damage model, damage induces the global softening while plasticity reproduces quantitatively the evolution of the irreversible strains. Experimental and numerical unloading slopes ( $E^{\prime}$ in Eq. (17)) are now similar.

\subsection{Influence of damage on permeability}

Different laws governing the evolution of permeability with the degradation of the material have been proposed, e.g. by Sugiyama et al. (1996b) or Fauchet (1991) based on plastic strains. As mentioned earlier, a theoretical background for the correlation between damage and permeability in the diffuse regime exists (Chatzigeorgiou et al., 2005). The variation of the permeability of a damaged sample (unloaded) is related to the variation of its elastic stiffness (and thus to its mechanical damage). Three equations have been proposed in the literature that relate the intrinsic permeability with damage. The first one is due to Gawin et al. (2003) and it is based on an experimental calibration from (Bary, 1996):

$K=K_{0} 10^{A_{\mathrm{D}} D}$

where $D$ is the damage and $K_{0}$ the permeability of the safe sample. $A_{\mathrm{D}}$ is a parameter of the model. The second law from Picandet et al. (2001) presents an exponential form

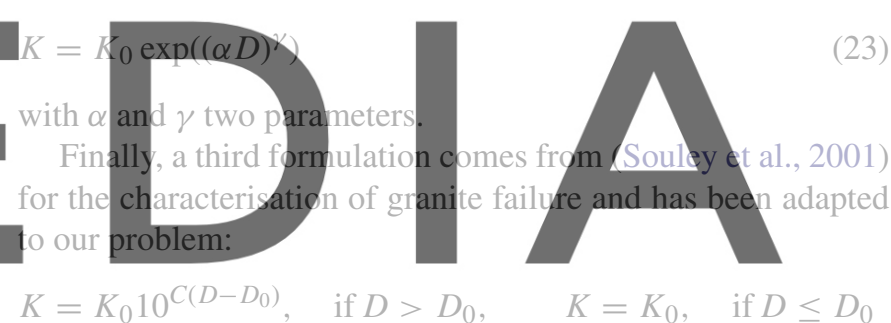

$K=K_{0} 10^{C\left(D-D_{0}\right)}, \quad$ if $D>D_{0}$

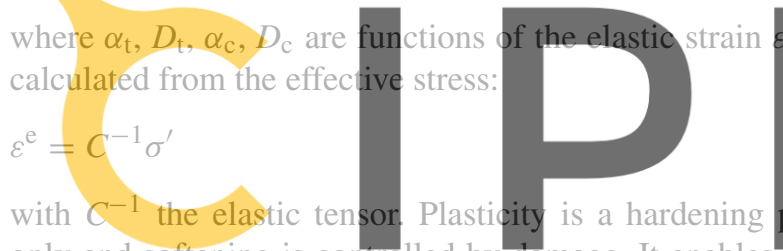

only and softening is controlled by damage. It enables to ease the numerical implementation and the calibration of the parame-

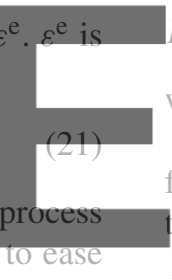

$K=K_{0}$, if $D$
watermark

implementation can be found in Jason et al. (2006).

To highlight the interest of including plasticity in a damage formulation, Fig. 6 shows the comparison for a cyclic compression test between the experimental results (Sinha et al., 1964), the pure damage model (based on the initial formulation developed by Mazars (1984) with $\varepsilon=\varepsilon^{\mathrm{e}}$ ) and the elastic plastic damage law. If irreversible effects are not taken into account (Fig. 6a), with $C$ and $D_{0}$ two parameters. In Eq. (24), a threshold in the damage is clearly defined from which an evolution of the permeability is observed.

These three relationships are compared with the experimental results from (Picandet et al., 2001) in Fig. 7. It corresponds to gas permeability measurements on unloaded specimens after a
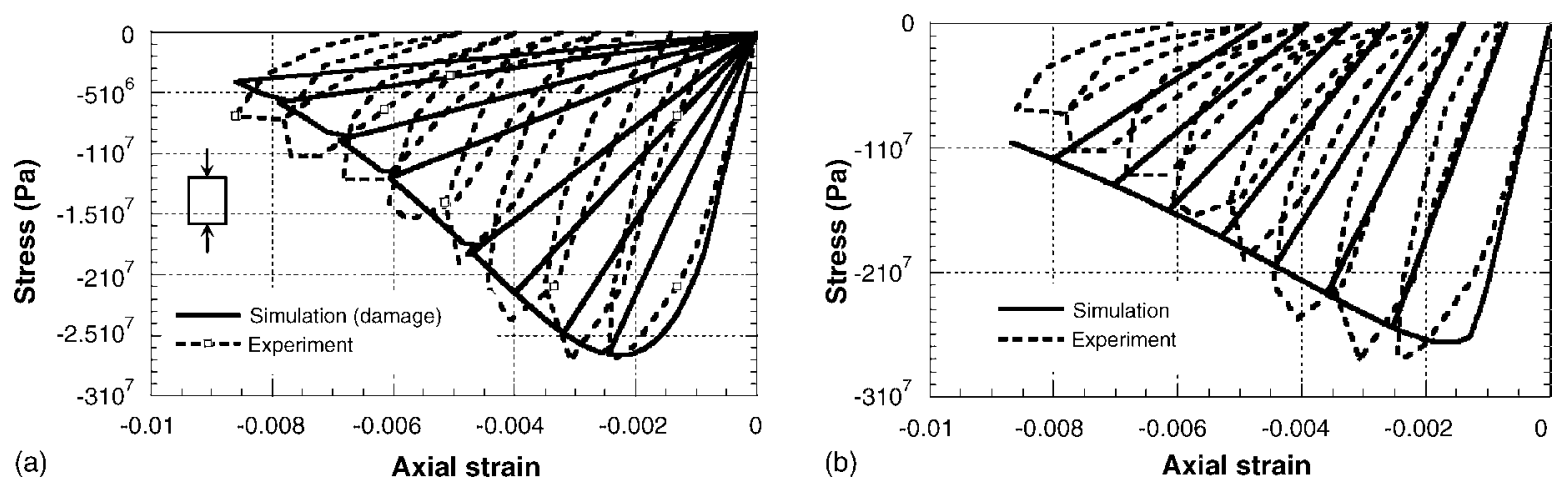

Fig. 6. Simulation of a cyclic compression test (Sinha et al., 1964). Elastic damage response (a) and elastic plastic damage simulation (b), after Jason et al. (2006). 

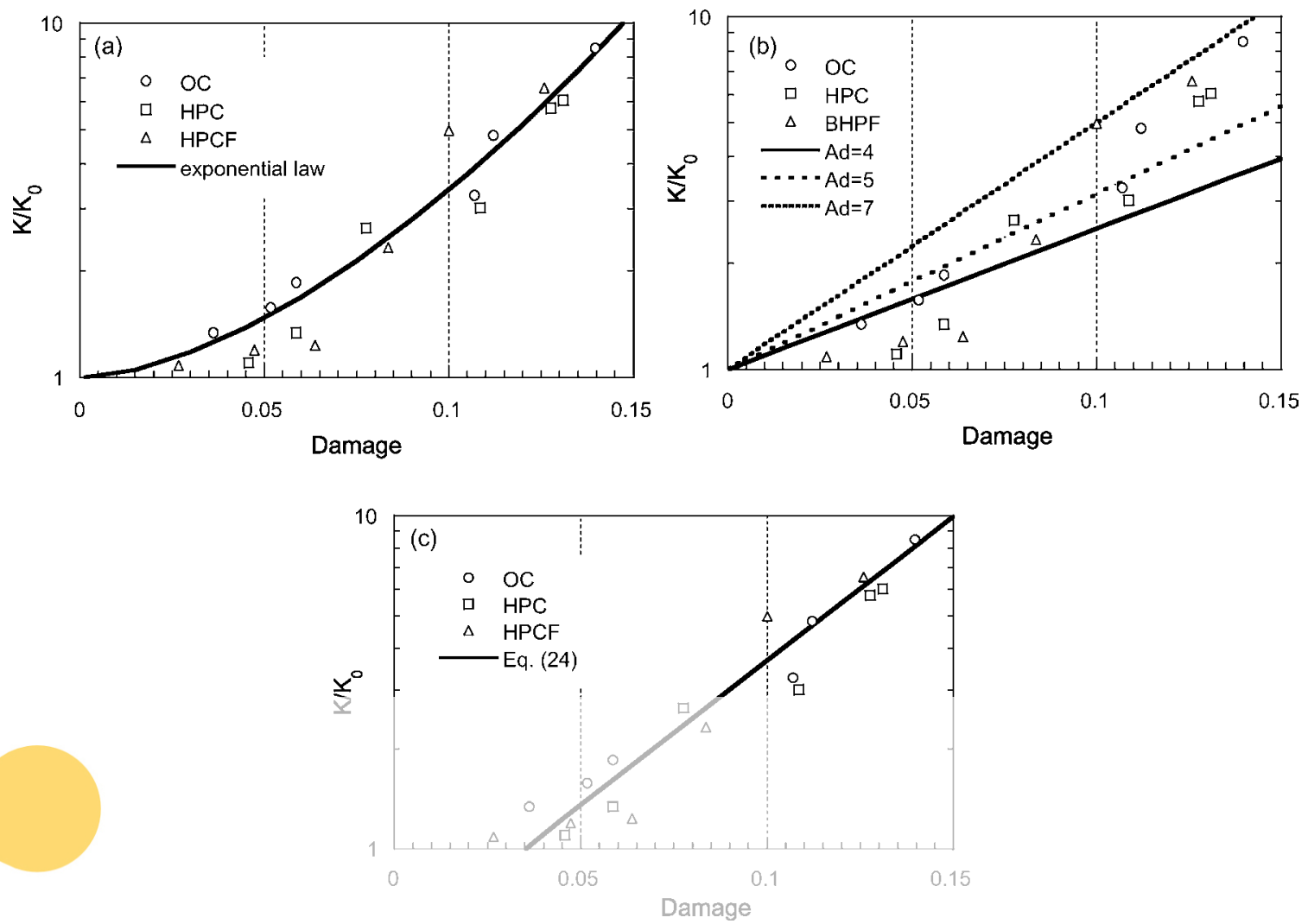

Fig. 7. Evolution of the intrinsic permeability with damage: (a) calibration with the exponential equation (23) $(\alpha=11.3, \gamma=1.64)$, (b) calibration with Eq. (22) for different values of $A_{D}$ and (c) calibration with Eq. (24) $\left(C=8.67, D_{0}=0.035\right)$

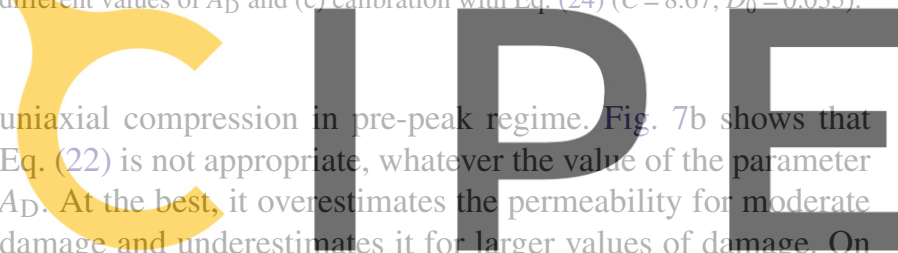

damage and underestimates it for larger values of damage. On the contrary, the relations based on Eqs. (23) and (24) are capable

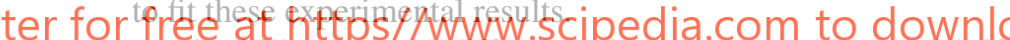
Fig. 8 illustrates the differences between Eqs. (23) and (24) if high values of damage are considered (post-peak regime). The experimental data have been obtained by Bary (1996) during a BIPEDE test that aims at producing "homogeneous" tension (see

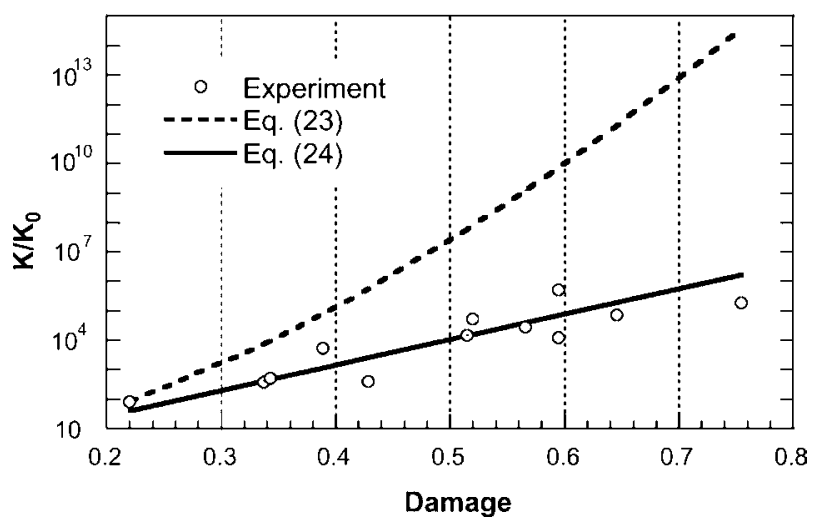

Fig. 8. Evolution of the intrinsic permeability with damage. Comparison of Eq. (23) and (24) (see Fig. 7 for the parameters). Experimental results from Bary (1996).

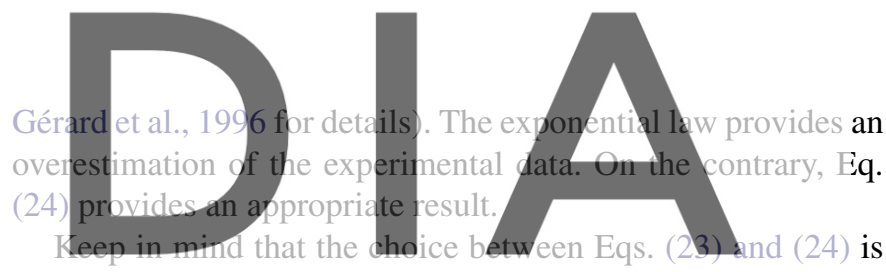

not so obvious. Indeed, for high values of damage (and local-

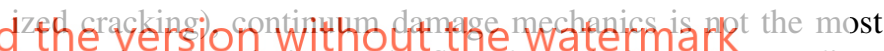
appropriate description as the flow through the porous medium is rather governed by the opening of macro-cracks. Moreover, the reproducibility of the experimental resuits in the post-peak regime has to be proven. Finally, these formulations are not entirely satisfactory from an experimental point of view. During unloading, the value of the experimental damage keeps constant while permeability decreases (Meziani and Skoczylas, 1999 or Torrenti et al., 1999). This phenomenon can not be taken into account by a simple evolution $K=f(D)$ and information about the stress or strains should be included. Nevertheless, once again, due to a lack of detailed experimental data, and for the purpose of devising an approximate computational scheme, Eq. (24) has been used for the evolution of the intrinsic permeability as a function of the mechanical damage. The total gas permeability is written as

$$
\begin{aligned}
& K_{\mathrm{g}}=K_{0}\left(1-S_{1}\right)^{4.5}\left(1-S_{1}^{2}\right), \quad \text { if } D<0.035, \\
& K_{\mathrm{g}}=K_{0}\left(1-S_{1}\right)^{4.5}\left(1-S_{1}^{2}\right) \times 10^{8.67 D-0.3}, \quad \text { if } D \geq 0.035
\end{aligned}
$$




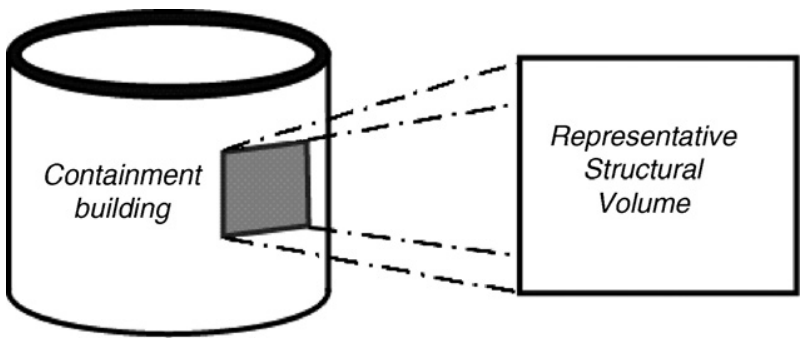

Fig. 9. Position of the extracted representative structural volume (RSV).

\section{Application}

The application presented here has been proposed by Electricité de France. The test, named PACE 1300, is a representative structural volume (RSV) of a pre-stressed pressure containment vessel (PPCV) of a French 1300 MWe nuclear power plant (Jason et al., 2004b). Fig. 9 illustrates the location of the RSV within the entire PPCV structure. The model incorporates almost all components of the real structure: concrete, vertical and horizontal reinforcement bars, transversal reinforcements, and pre-stressed tendons in both horizontal and vertical directions. The size of the RSV is chosen large enough to include a sufficient number of components (specially pre-stress tendons) and to offer a significant observation area in the centre, far enough from geometrical singularities in the structure, while remaining as small as possible to ease computations.

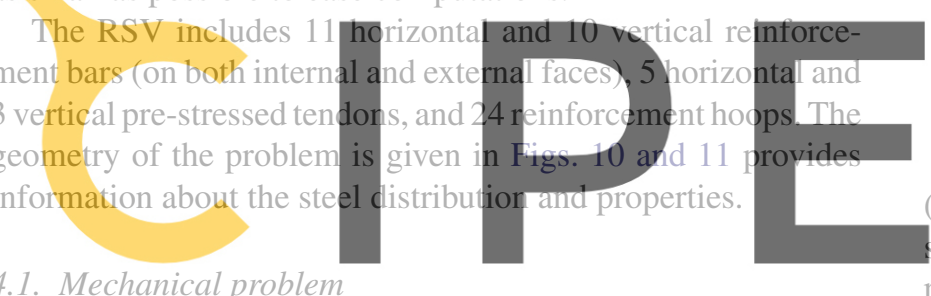

4.1. Mechanical problem

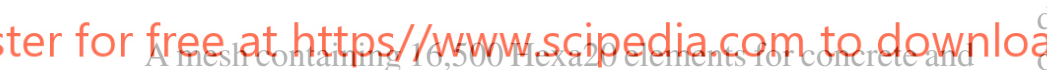

1200 bar elements for reinforcement bars and tendons is used. For the computation, the elastic plastic damage constitutive law

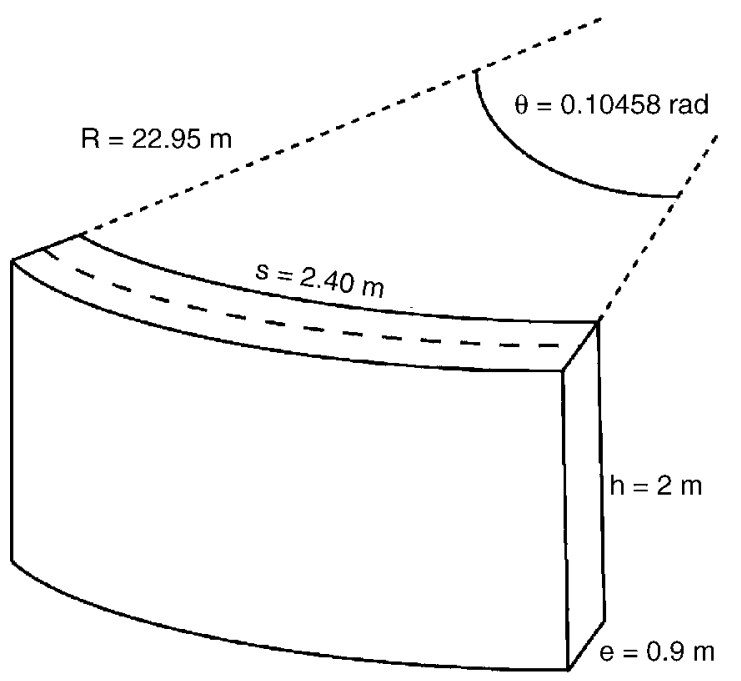

Fig. 10. Geometry of the representative structural volume (RSV).
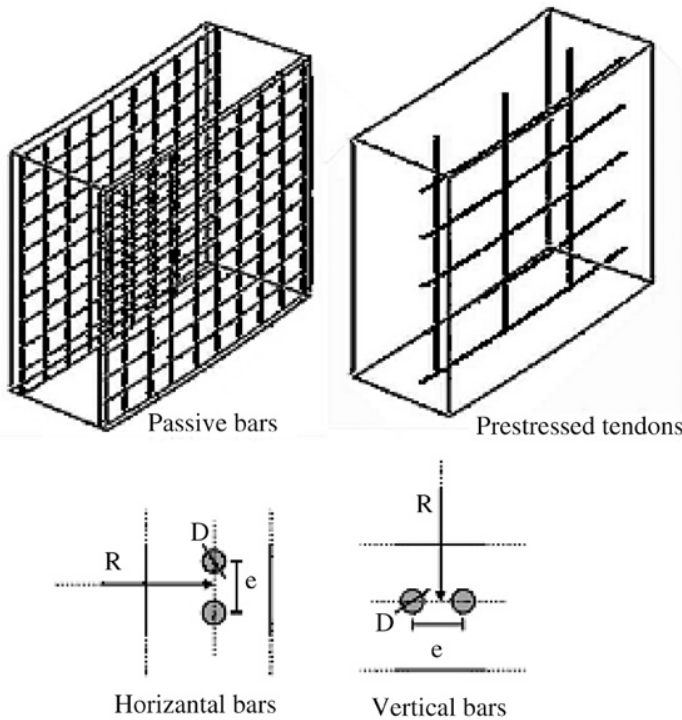

Horizantal bars

Vertical bars
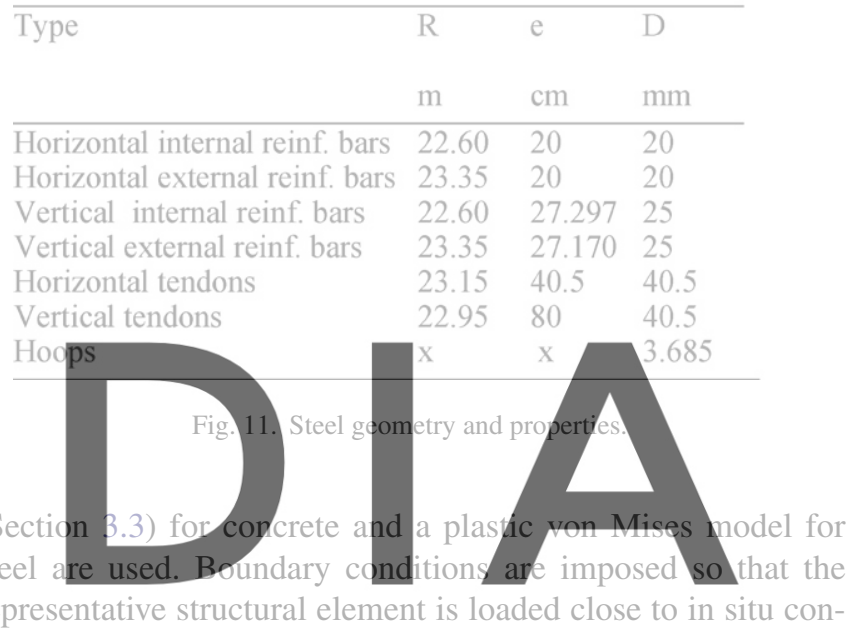

epresentative structural element is loaded close to in situ conditions during an integrity test: face $\mathrm{SB}$ is blocked along $\mathrm{OZ}$; face SH all the nodes are restranted to fofow the same dis placement along OZ; no rotations are allowed for faces SG and SD (see Figs. 12 and 13). In order to model the effect of prestressed tendons, bar elements are anchored to faces SG and SD for horizontal cables and to faces SB and SH for vertical tendons, then pre-stressed using internal forces. These elements are restrained to surrounding concrete elements to represent the pre-stressing technology applied in French PPCVs. The integrity test loading is represented by a radial pressure on the internal face SI and the bottom effect applied on face SH (ten-
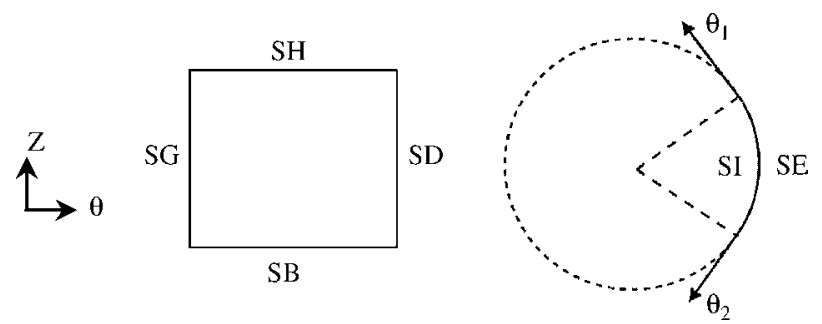

Fig. 12. Definition of the F.E. model indicating the boundary SG, SD, SH and SB. 


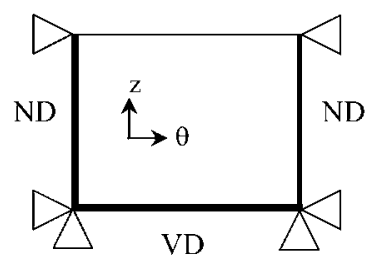

Boundary conditions in displacement

ND : zero normal displacement VD : zero vertical displacement
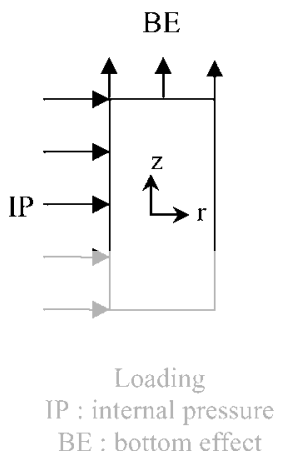

Fig. 13. Boundary conditions and loading for the representative volume.

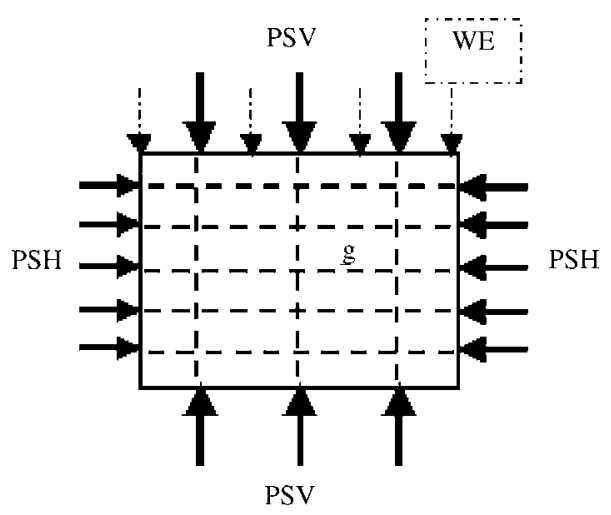

Boundary conditions in stress PSH : horizontal prestress $5.28 \mathrm{MN}$ per tendon PSV : vertical prestress $6.93 \mathrm{MN}$ per tendon WE : structure weight $1.61 \mathrm{MPa}$ $\mathrm{g}$ : gravity sile stress proportional to effect of the neighboring and that of the surroundir account.

Results concerning th structure can be found i parameters as well. In our study, only the damage distribution is considered for the subsequent hydraulic computation. The dis- internal pressure point) has been chosen to emphasize the effect of damage. Nevertheless, it stays in the intial domain of validity of the method as the localized damage band does not go through the total thicknes (see Section 2.1). It should be ppinted out that this computation is ocal. The localization of damage and strains due to strain softening would requive the use of a regularization technique (P1jaudier-Cabot and Bazant, 1987; Peerlings et al., 1996; Lorentz and Andrieux, 2003) to avoid mesh dependency

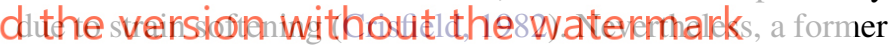
study (Jason et al., 2004b) has shown that using such a technique would be numerically too expensive. That is why only
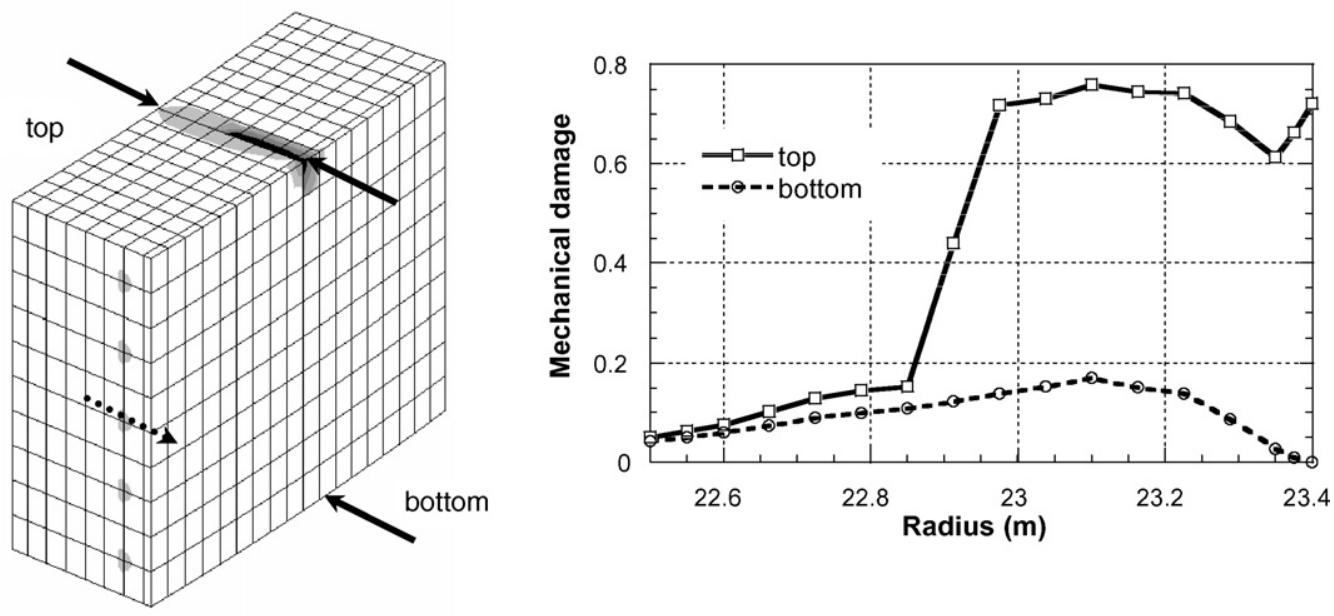

Fig. 14. Damage distribution in the representative structural volume (a) and along two horizontal lines (top and bottom). Grey zones correspond to a damage between 0.5 and 0.8. D is near from 1 in black zones. Damage is interpolated at each node then averaged to obtain the value given through the cross lines. 


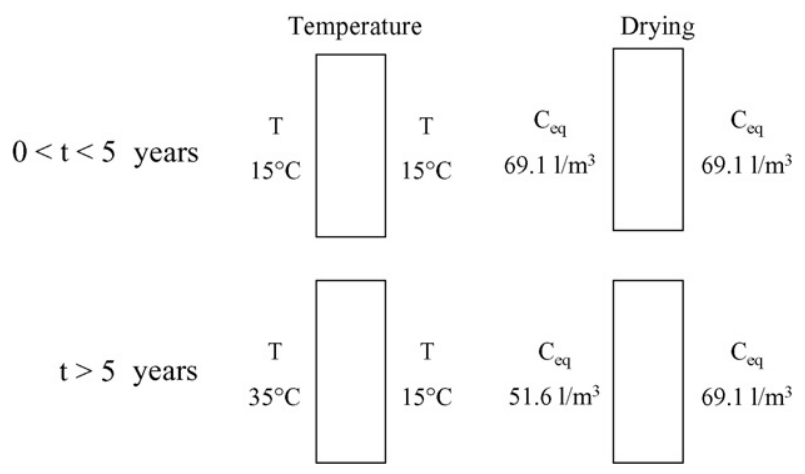

Fig. 15. Boundary conditions for the thermal and drying computations.

local simulations are considered and the method will be used as a qualitative tool.

\subsection{Drying problem}

In the drying problem, the following boundary conditions are considered: for the preliminary determination of the temperature $T$ (Eq. (10)), the temperatures in the inner and outer faces are kept constant, equal to $15^{\circ} \mathrm{C}$. From the fifth year, the internal temperature increases until $35^{\circ} \mathrm{C}$ (Fig. 15). For drying simulations, the boundary conditions are expressed with humidity flows $w^{\mathrm{fl}}$ through the internal and external surfaces, following (Granger, 1995):

\footnotetext{
$w^{\mathrm{fl}}=\frac{0.5 \beta}{C_{0}-C_{\mathrm{eq}}}\left[C^{\mathrm{fl}}-\right.$
}

where $\beta$ is a parameter, $\varnothing$

the water content corresp on

parameters chosen for the s
correspond to a numerical c

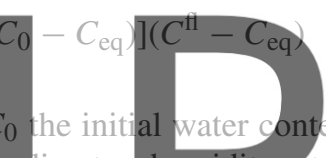
nulation are listed in Tab.

alibration carried out by

(1995) in the past for a French nuclear power plant. Fig. 16
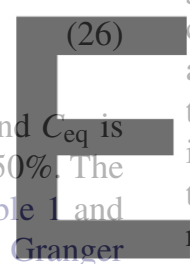

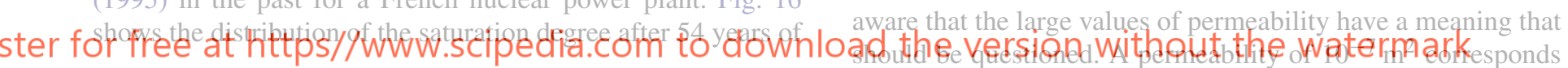

Table 1

Parameters for thermal, hydrous and hydraulic computations

\begin{tabular}{ll}
\hline Thermal computation (Eq. (10)) & \\
$\lambda_{\mathrm{T}}\left(\mathrm{W} /\left(\mathrm{m}^{\circ} \mathrm{C}\right)\right)$ & 8000 \\
$\rho C_{\mathrm{p}}\left(\mathrm{J} /\left(\mathrm{m}^{3}{ }^{\circ} \mathrm{C}\right)\right)$ & $2.4 \times 10^{6}$ \\
& \\
Drying computation & \\
$\quad$ Diffusive coefficient (Eq. (11)) & $3.8 \times 10^{-13}$ \\
$\quad A$ & 0.05 \\
$B$ & 0 \\
$T_{0}\left({ }^{\circ} \mathrm{C}\right)$ & 4700 \\
$Q_{i} / K(\mathrm{~K})$ & \\
Boundary condition (Eq. (26)) & 105.7 \\
$C_{0}\left(1 / \mathrm{m}^{3}\right)$ & $3.4 \times 10^{-8}$ \\
$\beta$ & \\
Saturation degree (Eq. (12)) & 105.7 \\
$C_{s a t}\left(1 / \mathrm{m}^{3}\right)$ & \\
& \\
Hydraulic computation (Eqs. (6) and (25)) & 0.105 \\
$\Phi$ & $1.8 \times 10^{-5}$ \\
$\eta_{\mathrm{g}}(\mathrm{kg} /(\mathrm{m} \mathrm{s}))$ & $10^{-16}$ \\
$K_{0}\left(\mathrm{~m}^{2}\right)$ & \\
\hline
\end{tabular}

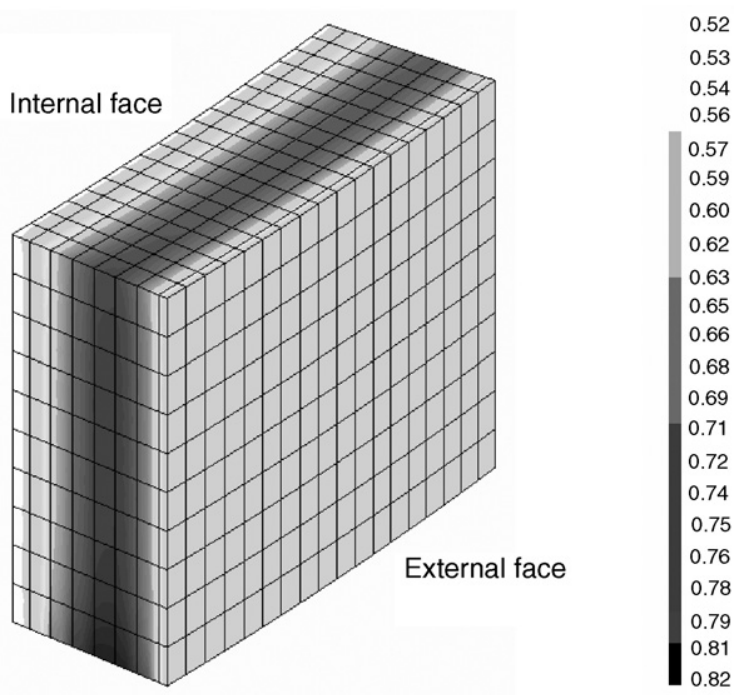

Fig. 16. Distribution of the saturation degree in the representative structural volume.

drying. It is not symmetric within the thickness due to a non symmetry of the imposed boundary conditions.

\subsection{Hydraulic problem}

From the distribution of the saturation degree and damage, the gas permeability can be computed using Eq. (25) (Fig. 17). It is clearly influenced both by danage and saturation. One can notice a "localized" band on the top of the structure corresponding to the damage localized band. Moreover, the hydraulic conductivity is higher on the inner and outer layers of the panel than in the corre of the volume due to change in the water content. It esults in a high range in the values of the transfer property, from $10^{-20}$ to $10^{-1} \mathrm{~m}^{2}$. As mentioned in Section 3.4, one has to be

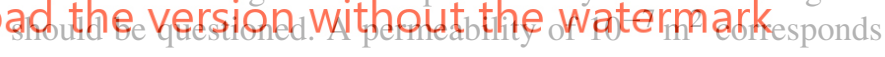

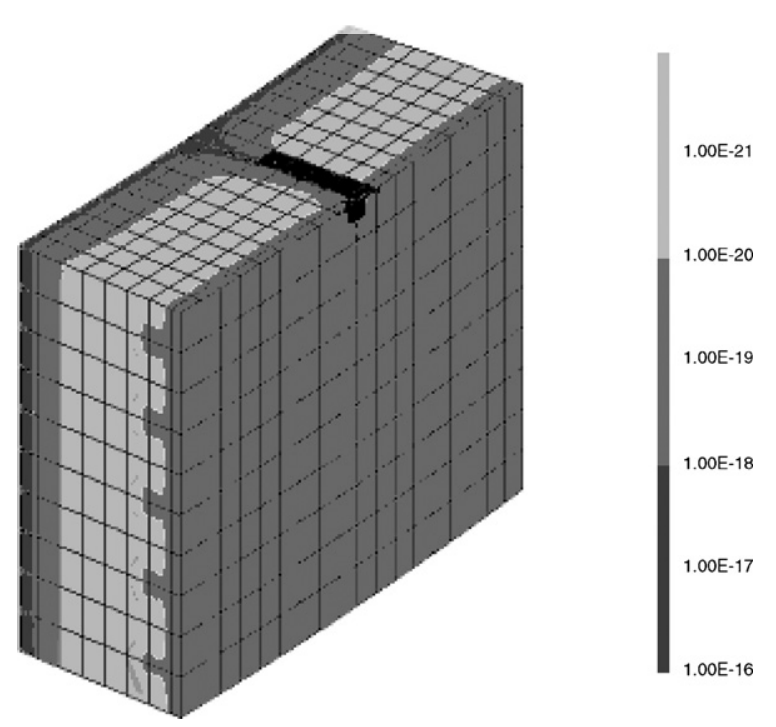

Fig. 17. Permeability distribution in the representative structural volume. Black zones correspond to a permeability equal to $10^{-7} \mathrm{~m}^{2}$. 
to the permeability of a dry sand and not of concrete. Our aim is to provide qualitative information about the hydraulic behavior of the structure. Without further knowledge on the evolution of the material permeability when concrete is severely damaged, viewed as a continuum rather than as a cracked material, it is difficult to justify such extreme values.

The hydraulic gas pressure is then applied in two steps:

- First a regular increase in the internal pressure from $0.1 \mathrm{MPa}$ (atmospheric pressure) to $0.58 \mathrm{MPa}$ (integrity tests) in 200 time steps until $t=3.6 \mathrm{~s} \mathrm{(} \Delta t=0.018 \mathrm{~s}$ ) (external pressure constant equal to the atmospheric pressure).

- Then a constant $0.58 \mathrm{MPa}$ internal pressure during 600 time steps until a variable $t_{\text {end }}$.

Zero flow conditions are added on lateral faces of the structure (Fig. 18).

Fig. 19 shows the distribution of pressure within the thickness of the structure during the second phase (constant 0.58 MPa pressure) on the top, middle and bottom of the structure, as defined by Fig. 18 , for $t_{\text {end }}=7200 \mathrm{~s}$. Fig. 20 shows the same illustration for $t_{\mathrm{end}}=2 \times 10^{6} \mathrm{~s}$. For $t_{\mathrm{end}}=7200 \mathrm{~s}$, the permanent regime is not reached. Oscillations that are probably due to the large range of variation of the permeability are present even if they become less and less significant with an increasing time. The behaviors are globally similar for each considered height. For $t_{\text {end }}=2 \times 10^{6} \mathrm{~s}$, a permanent state is quickly reached at the top of the structure. The pressure in the localized damage band keeps a constant value equal to $0.1 \mathrm{MPa}$ (atmospheric pressure). This result can be explained by the high permeability observed in this zone that triggers a fast transfer through the concrete compared

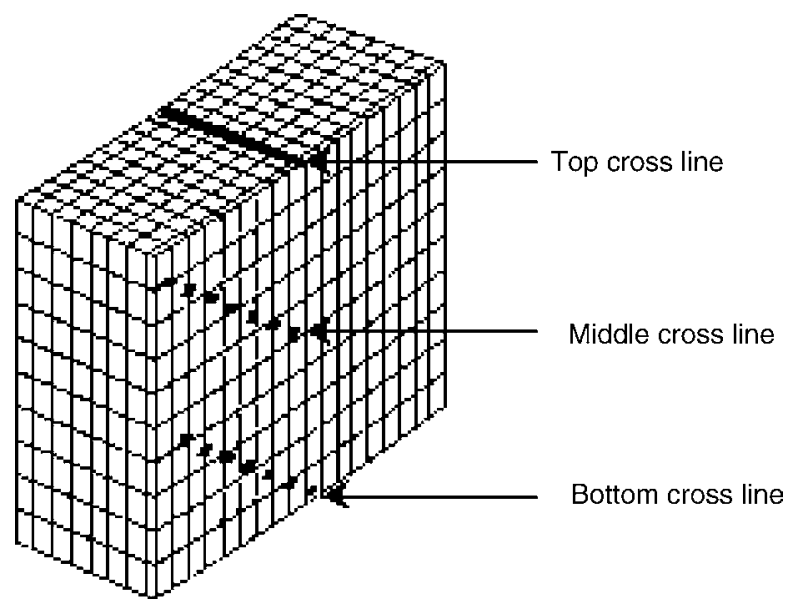

Fig. 18. Definition of the cross lines for the evolution in time of the internal pressure in the depth of the volume (top and middle cross lines) during the increase in the hydraulic loading.

with the middle and bottom of the RSV. On these two cross lines, the behaviors are globally identical even if the damage noticed (see Fig. 14) in the bottom creates some differences in the distribution

To confirm these local results, Fig. 21 shows the evolution of the pressure in time in the entire volume. A band of pressure equal to $0.1 \mathrm{MPa}$ is created on the top, corresponding to the high damaged zone. Outside this critical place, the hydraulic pressure is more regular.

These distributions of pressure provide some information about the hydraulic behaviour of the structure. Nevertheless, in an industrial context, there are not totally sufficient. In order to locate the zones to be repaired, that is to say with a heavy
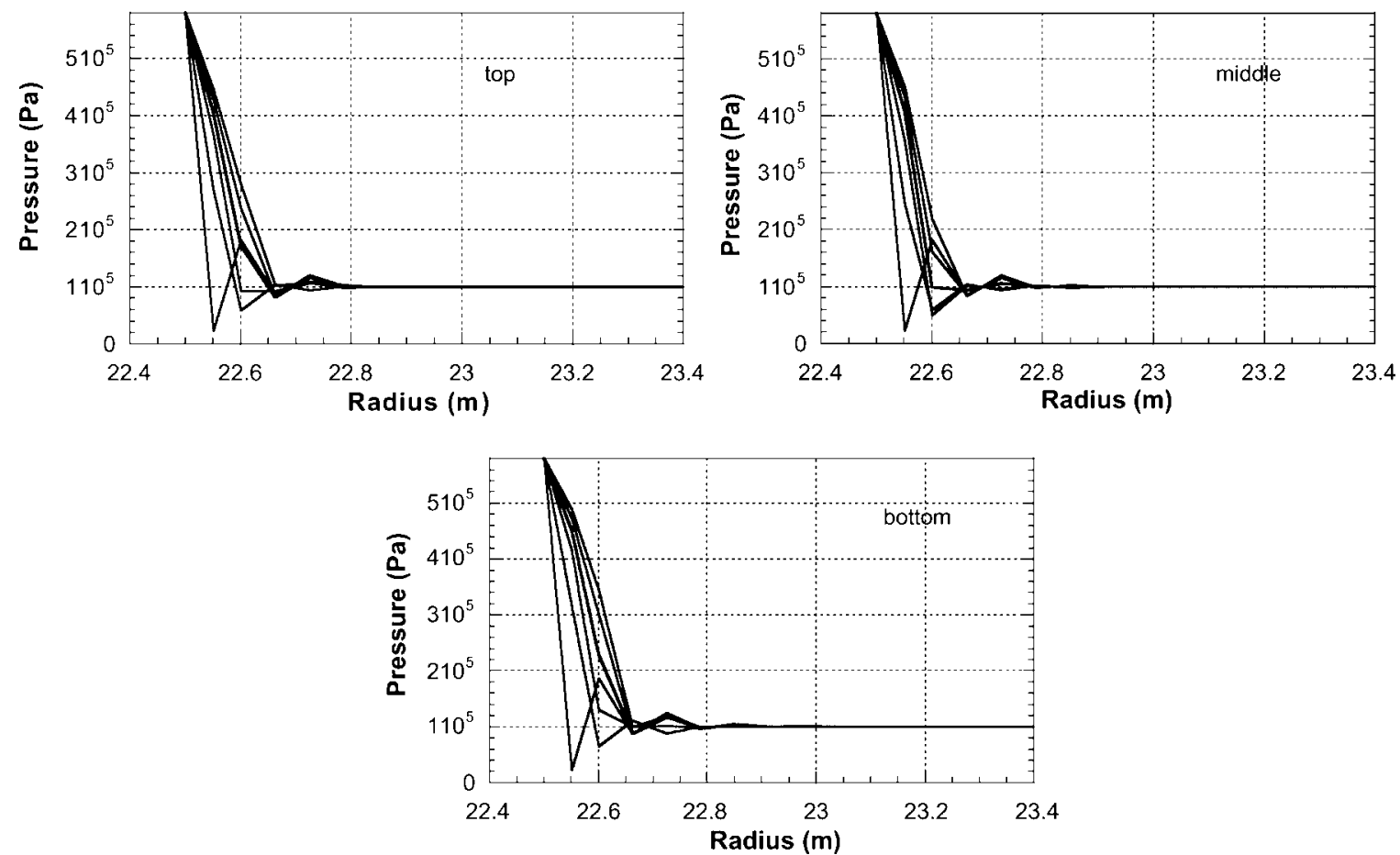

Fig. 19. Evolution in time of the pressure in the depth of the structure (applied internal pressure constant equal to $0.58 \mathrm{MPa}$ with $t_{\mathrm{end}}=7200 \mathrm{~s}$ ). 

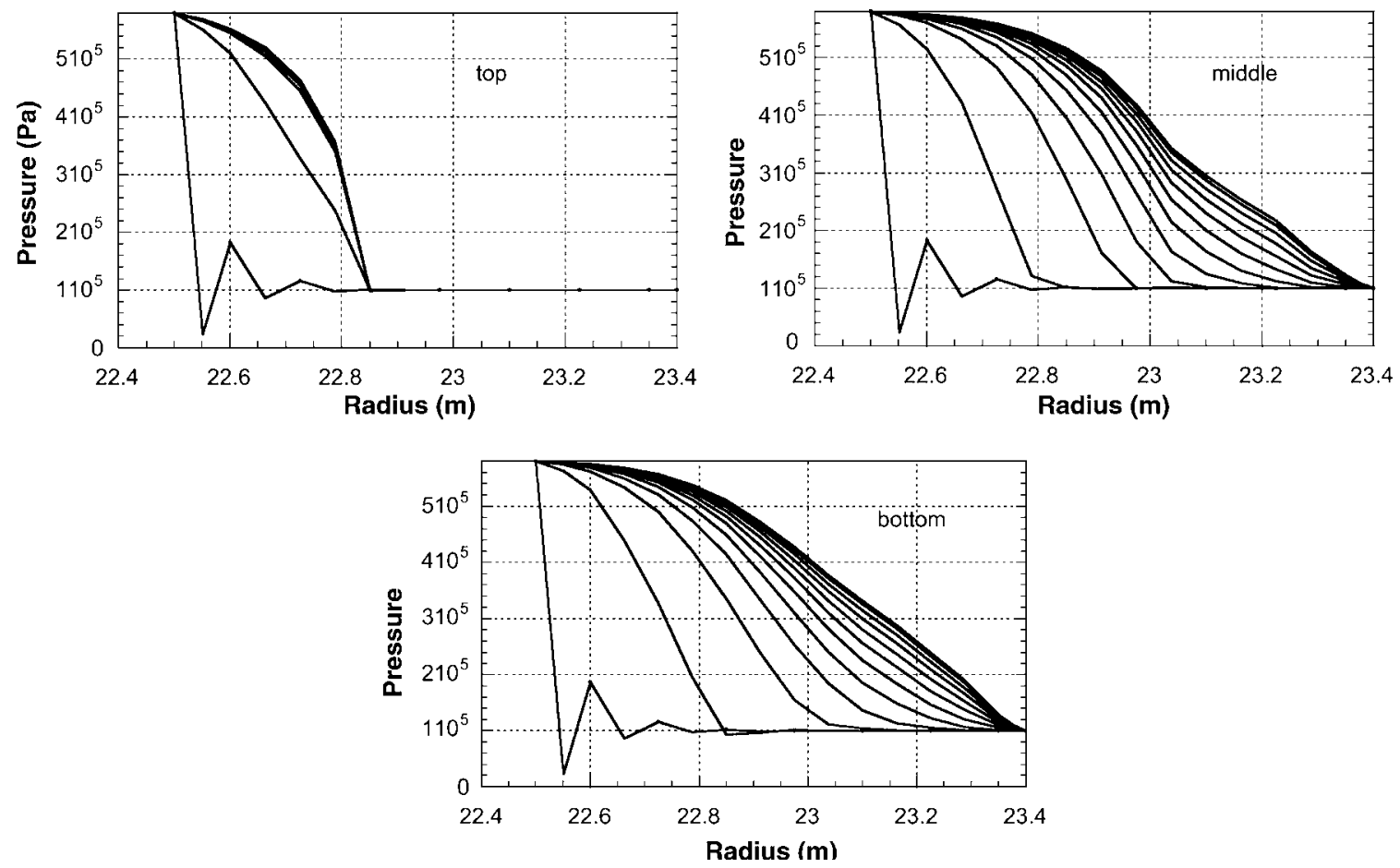

Fig. 20. Evolution in time of the internal pressure $(\mathrm{Pa})$ in the depth of the structure (applied internal pressure constant equal to $0.58 \mathrm{MPa}$ with $t_{\mathrm{end}}=2 \times 10^{6} \mathrm{~s}$ ).
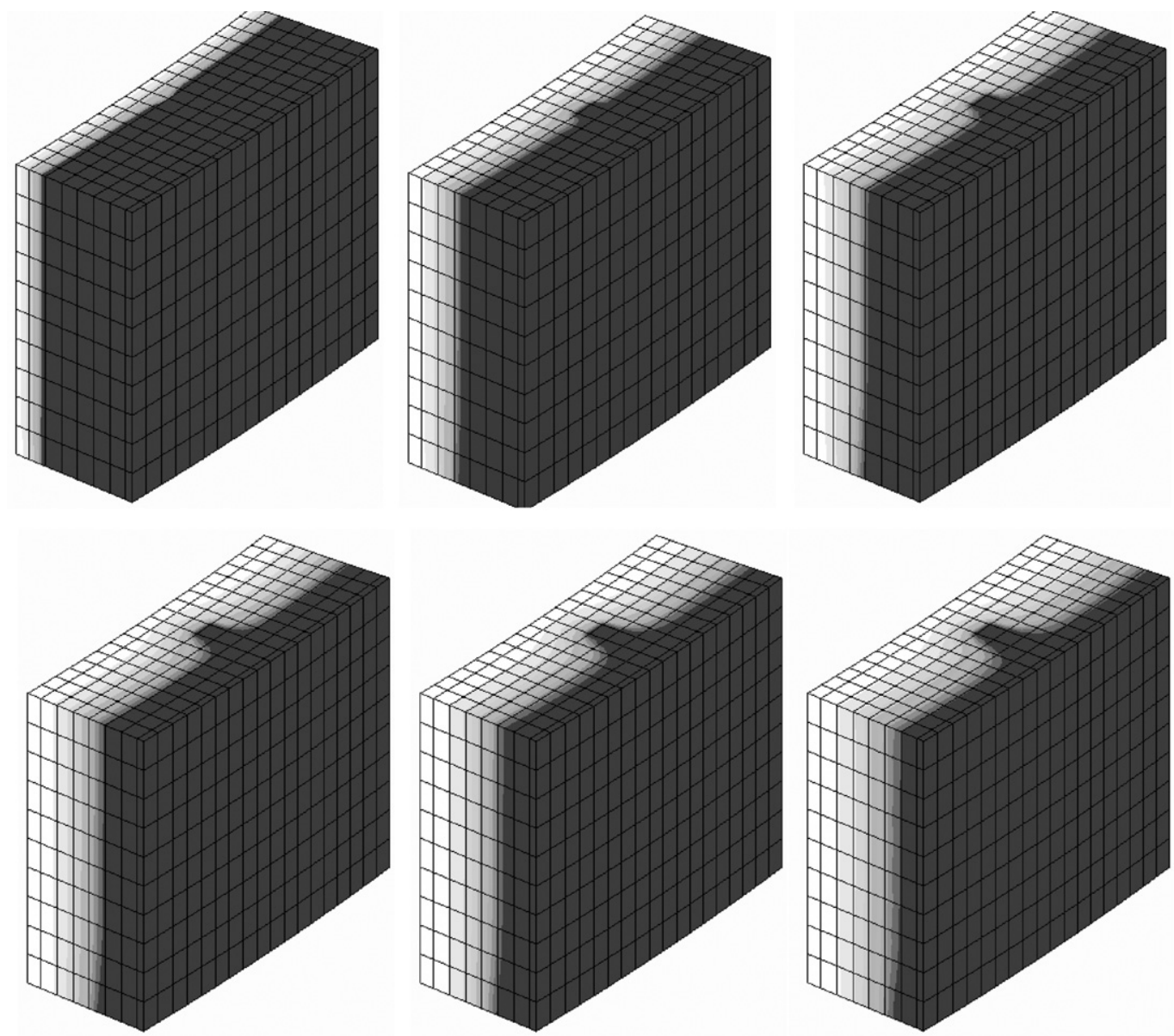

$1-00 E+05$

$1-48 \mathrm{E}+05$

$1-96 \mathrm{E}+05$

$2-44 E+05$

2-92E+05

$3-40 E+05$

$3-88 E+05$

$4-36 \mathrm{E}+05$

4-84E+05

$5-32 E+05$

$5-80 \mathrm{E}+05$

Fig. 21. Evolution of the pressure distribution inside the volume with time. 


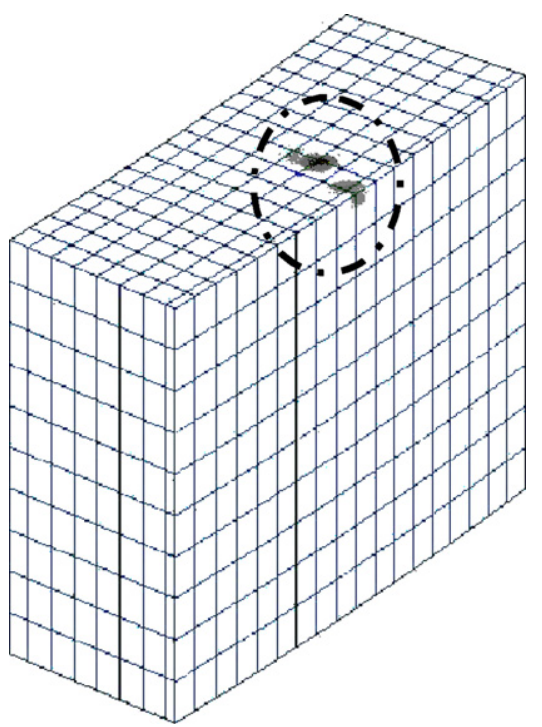

Fig. 22. Repartition of the axial flow in the representative structural volume. Dark zones correspond to the highest values of the hydraulic flow.

leaking rate, an indicator has to be defined. The radial flow is an adequate candidate because it is representative of the gas volume which could be rejected in environment.

An indicator $\left(\mathrm{kg} \mathrm{s}^{-3}\right)$, proportional to the flow, is thus calculated using the equation:

ind $=-\lambda_{\mathrm{P}}\left(P_{\mathrm{g}}\right) \nabla\left(P_{\mathrm{g}}\right)$

Fig. 22 illustrates the distribution of this indicator at the end of the computation $\left(t_{\mathrm{end}}=2 \times 10^{6} \mathrm{~s}\right)$. It concentrates around the highly permeable zone (top of the structure) with values near zero outside this critical zone.

\subsection{Elements on the numerical sensitivity}

In order to study the influence of the numerical parameters (time and space discretisation for example), the representative structural volume is simplified using a one-dimensional approach. A bar, whose dimensions are given in Fig. 23, is divided in nine parts, one finite element having a size $\Delta x$ of $0.1 \mathrm{~m}$. The idea is to attribute to each part of the bar a different value of the damage and degree of saturation to be representative of fluid flow through the RSV.

The chosen distributions are given in Fig. 24. It aims at reproducing the evolution noticed at the top of the structure. The repartition of pressures along the $x$ axis are illustrated in Fig. 25. The loading sequence for the gas pressure is kept the same. The value of the time step has little influence during the increase of pressure and only the space discretisation seems to provide

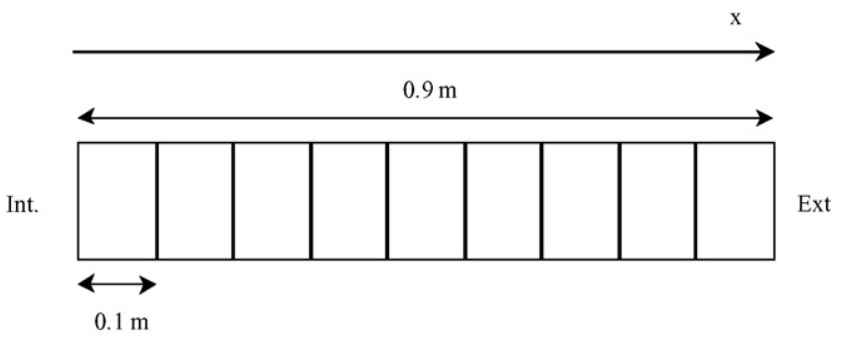

Fig. 23. Unidimensional approach. The bar is divided in nine parts. "Int." stands for the internal face while "ext." stands for the external one.

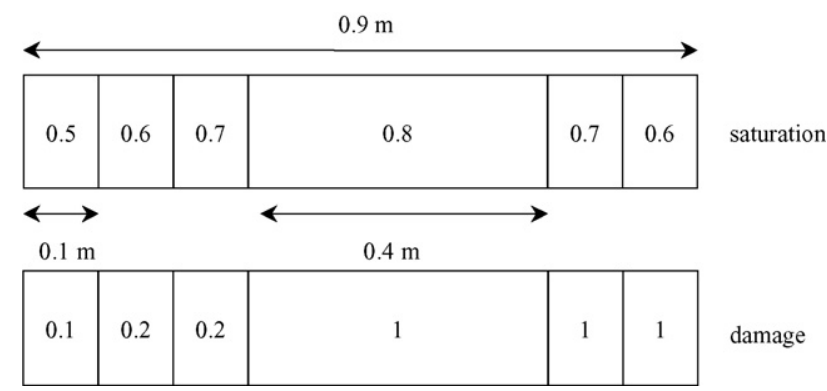

Fig. 24. Saturation and damage distributions in the unidimensional approach.

an adequate solution to the oscillatory response observed in the previous section. With 90 elements in the depth (element size $\Delta x=0.01 \mathrm{~m}$ ), the oscillations appear for the first time step and along the first $\Delta x$. The global numerical response is thus more acceptable. Nevertheless, it is difficult to think about such a mesh fineness for the three-dimensional behaviour of the RSV. Nevertheless, the origin of the numerical troubles has been identified and a solution is available provided computing facilities are available.

In order to exhibit the influence of the evaluation of damage on the hydraulic response, a cube is loaded in uniaxial compression and a hydraulic gas pressure is applied (Fig. 26). For the sake of simplicity, the degree of saturation is kept constant equal to $15 \%$, only mechanical conditions may vary. Two models are considered, the elastic plastic damage formulation and the standard damage constitutive law proposed by Mazars (1984). These models are calibrated such that they fit the same stress-strain response in compression and tension. Table 2 illustrates the differences observed on the mechanical and hydraulic results. The pure damage model yields an axial flow indicator that is ten times higher than the one obtained with the other. The damage model overestimates the decrease of the unloading stiffness (and thus the value of the damage) and this yields, after the use of Eq. (25) a large variation of permeability compared to the elastoplastic damage model which better estimates unloading. As the indicator of the flow is directly calculated from the value of the

Table 2

Comparison of the hydraulic responses with standard damage model and elastic plastic damage constitutive law

\begin{tabular}{lllllll}
\hline Model & $\varepsilon$ & $\sigma(\mathrm{Pa})$ & $D$ & $S_{\mathrm{l}}$ & $K_{\mathrm{g}}{ }^{\mathrm{a}}\left(\mathrm{m}^{2}\right)$ & ${\text { Flow indicator }\left(\mathrm{kg} \mathrm{s}^{-3}\right)}$ \\
\hline Damage & -0.002 & $-2.64 \times 10^{7}$ & 0.3641 & 0.15 & $3.38 \times 10^{-14}$ & $2 \times 10^{3}$ \\
Plastic-damage & -0.002 & $-2.54 \times 10^{7}$ & 0.2327 & 0.15 & $2.46 \times 10^{-15}$ & $1.45 \times 10^{2}$ \\
\hline
\end{tabular}

${ }^{\text {a }}$ Initial permeability is equal to $10^{-16} \mathrm{~m}^{2}$. 



Fig. 25. Influence of time and space steps on the oscillations: (a) and (b) time step influence; (a) and (c) space step influence.

(a)



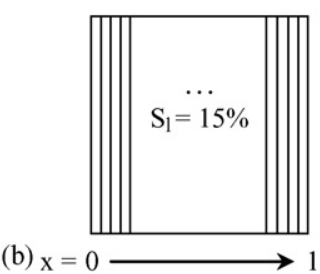

(b) $\mathrm{x}=0 \longrightarrow$

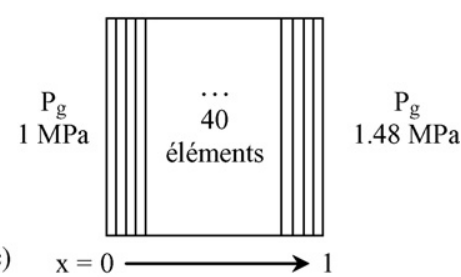

(c)

Fig. 26. Methodology for the cube. Application of a compressive loading (a), constant degree of saturation (b) and application of a gas hydraulic pressure (c).

permeability, it finally also gives a large variation of this variable. As a conclusion, the choice for the mechanical constitutive law is crucial if a misevaluation of the experimental damage needs to be avoided.

\section{Conclusions}

This contribution aimed at proposing a simplified methodology to study the hydraulic behaviour of structures like containment buildings of nuclear power plants. An alternative to the fully coupled solutions, that are theoretically more complete with cross effects between thermal drying and mechanical phenomena but also more elaborated, has been described. It is based on a chained approach with two preliminary independent mechanical and drying computations followed by a hydraulic computation which is in fact the association of Darcy law combined with gas mass balance equation. The key of this methodology is the determination of evolutions between 
damage, saturation and the hydraulic conductivity. Starting from experimental results proposed in literature, two relations between damage and intrinsic permeability and between degree of saturation and gas relative permeability have been defined. They reproduce quantitatively, for pre-peak regime (low damage values), and qualitatively for post-peak regime (high damage values), the evolution of the transfer property due to drying and mechanical loading.

The methodology has been applied to a representative structural volume of a containment building for nuclear power plants. For industrial purpose, a leakage indicator based on radial flow has been proposed. The methodology proposed in this contribution represents a simplified alternative to fully coupled formulations. It needs, however, to be backed in the future by some experimental validation studies to validate damage-saturation-permeability relations and to evaluate the influence of the basic assumptions of the chained approach.

\section{Acknowledgements}

Partial financial supports from EDF and from the EU through MAECENAS project (FIS5-2001-00100) are gratefully acknowledged. The authors particularly thank R. Crouch (University of Sheffield) for his help in the design and the numerical development of the plasticity model. The authors would like to thank EDF for scientific support toward the developments in the FE code "Code_Aster" and the Spanish-French sponsorship HF2003-0041.

\section{References}

Abbas, A., Carcasses, M., Ollivier, J.P., 1999. Gas permeability of concrete in relation to its degree on saturation. Mater. Struct. 32, 3-8.

Al Najim, A., Meftah, F., Mebarki, A., 2003. A non saturated porous medium approach for the modelling of concrete behaviour submitted to high temperatures. In: Bicanic, et al. (Eds.), Proceedings EUROC on Computational Modelling of Concrete Structures, pp. 521-530.

Baroghel-Bouny, V., Mainguy, M., Lassabatere, T., Coussy, O., 1999. Characterization and identification of equilibrium and transfer moisture properties for ordinary and high performance cementitious materials. Cement Concrete Res. 29, 1225-1238.

Bary, B., 1996. Etude du couplage hydraulique - mécanique dans le béton endommagé. PhD Thesis, LMT ENS Cachan, France.

Bary, B., Bournazel, J.P., Bourdarot, E., 2000. Poro-damage approach applied to hydro-mechanical fracture analysis of concrete. J. Eng. Mech. ASCE 126, 937-943.

Basheer, L., Kropp, J., Cleland, D.J., 2001. Assessment of the durability of concrete from its permeation properties: a review. Construction Buildings Mater. 15, 93-103.

Bazant, Z.P., Jirasek, M., 2002. Non local integral formulations for plasticity and damage, survey of progress. J. Eng. Mech. ASCE 128, 1119-1149.

Bear, J., 1991. In: Bear, J., Buchlin, J.-M. (Eds.), Mathematical modelling of transport in porous media. Modelling and applications of transport in porous media. Kluwer Academic, Boston, USA.

Chatzigeorgiou, G., Picandet, V., Khelidj, A., Pijaudier-Cabot, G., 2005. Coupling between progressive damage and permeability of concrete: analysis with a discrete model. Int. J. Num. Anal. Meth. Geomech. 29, 1005-1018.

Crisfield, M.A., 1982. Local instabilities in the non linear analysis of reinforced concrete beams and slabs. Proc. Inst. Civil Eng. 73, 135-145.

Crouch, R.S., Tahar, B., 2000. Application of a stress return algorithm for elasto plastic hardening softening models with high yield surface curvature. In: Onate, E., et al. (Eds.), Proceedings of European Congress on Computational
Methods in Applied Sciences and Engineering (CD-Rom). CIMNE Pubs., Barcelona.

Dal Pont, S., Ehrlacher, A., 2004. Numerical and experimental analysis of chemical dehydration, heat and mass transfers in a concrete hollow cylinder submitted to high temperatures. Int. J. Heat Mass Transfer 47, 135-147.

Debruyne, G., Cirée, B., 2001. Modélisation de la thermo hydratation, du séchage et du retrait du béton. Reference document R7.01.12, http://www.code-aster.org.

Etse, G., Willam, K., 1984. Fracture energy formulation for inelastic behavior of plain concrete. J. Eng. Mech. 120, 1983-2001.

Fauchet, B., 1991. Analyse poroplastique des barrages en béton et de leurs fondations. Rôle de la pression interstitielle, PhD Thesis, ENPC, France.

Gawin, D., Pesavento, F., Schrefler, B.A., 2003. Modelling of hygro-thermal behaviour of concrete at high temperature with thermo-chemical and mechanical material degradation. Comput. Meth. Appl. Mech. Eng. 192, 1731-1771.

Gens, A., Olivella, S., 2001. THM phenomena in saturated and unsaturated porous media. Revue Française de Génie Civil 5, 693-717.

Gérard, B., Breysse, D., Ammouche, A., Houdusse, O., Dirdry, O., 1996. Cracking and permeability of concrete under tension. Mater. Struct. 29, 141-151.

Granger, L., 1995. Comportement différé du béton dans les enceintes de centrales nucléaires, Analyse et modélisation. PhD Thesis, ENPC, France.

Grasberger, S., Meschke, G., 2000. A hygro thermal poroplastic damage model for durability analyses of concrete structures. In: Onate, E., et, al. (Eds.), Proceedings of the European Congress on Computational Methods in Applied Sciences and Engineering (CD-Rom). CIMNE Pubs., Barcelona

Jason, L., Huerta, A., Pijaudier-Cabot, G., Ghavamian, S., 2006. An elastic plastic damage formulation for concrete: applications to elementary tests and comparison with an isotropic damage model. Comput. Meth. Appl. Mech. Eng. 195 (52), 7077-7092.

Jason, L., Pijaudier-Cabot, G., Huerta, A., Ghavamian, S., 2004a. Damage and plasticity for concrete behavior. In: Neittaanmäki, P., Rossi, T., Korotov, S., Oñate, E., Périaux, J., Knörzer, D. (Eds.), Proceedings of Eccomas Conference (CD-Rom). CIMNE Pubs., Jyvaskyla, Finland.

Jason, L., Ghavamian, S., Pijaudier-Cabot, G., Huerta, A., 2004b. Benchmarks for the validation of a non local damage model. Revue Française de Génie Civil 8, 303-328.

Lorentz, E., Andrieux, S., 2003. Analysis of nonlocal models through energetic formulations. Int. J. Solids Struct. 40, 2905-2936.

Mainguy, M., Coussy, O., Baroghel-Bouny, V., 2001. Role of air pressure in drying of weakly permeable materials. J. Eng. Mech. 127, 1227-1238.

Mazars, J., 1984. Application de la mécanique de l'endommagement au comportement non linéaire et à la rupture du béton de structure. PhD Thesis, University Pierre et Marie Curie, France.

Mensi, R., Acker, P., Attolou, A., 1988. Séchage du béton: analyse et modélisation. Mater. Struct. 21, 3-12.

Meziani, H., Skoczylas, F., 1999. Experimental study of the mechanical behavior of a mortar and of its permeability under deviatoric loading. Mater. Struct. $32,403-409$.

Monlouis-Bonnaire, J.P., Verdier, J., Perrin, B., 2004. Prediction of the relative permeability to gas flow of cement based materials. Cement Concrete Res. $34,737-744$

Peerlings, R.H.J., de Borst, R., Brekelmans, W.A.M., De Vree, J.H.P., Spee, I., 1996. Some observations on localisation in non-local and gradient damage models. Eur. J. Mech. A Solids 15, 937-953.

Picandet, V., Khelidj, A., Bastian, G., 2001. Effect of axial compressive damage on gas permeability of ordinary and high performance concrete. Cement Concrete Res. 31, 1525-1532.

Pijaudier-Cabot, G., Bazant, Z.P., 1987. Nonlocal damage theory. J. Eng. Mech. $113,1512-1533$.

Sinha, B.P., Gerstle, K.H., Tulin, L.G., 1964. Stress Strain relations for concrete under cyclic loading. J. Am. Inst., 195-211.

Souley, M., Homand, F., Pepa, S., Hoxha, D., 2001. Damage induced permeability changes in granite: a case example ate the URL in Canada. Int. J. Rock Mech. Mining Sci. 38, 297-310.

Sugiyama, T., Bremmer, T.W., Holm, T.A., 1996a. Effect of stress on gas permability in concrete. ACI Mater. J. 93, 443-450. 
Sugiyama, T., Bremmer, T.W., Tsuji, Y., 1996b. Determination of chloride diffusion coefficient and gas permeability of concrete and their relationship. Cement Concrete Res. 26, 781-790.

Torrenti, J.M., Didry, O., Ollivier, J.P., Plas, F., 1999. La dégradation des bétons, couplage fissuration-dégradation chimique. Communications en mécanique. Hermes Pubs.

Van Genuchten, M.T., 1980. A closed form equation for predicting the hydraulic conductivity of unsaturated soils. Soil Sci. Soc. Am. J. 44, 892-898.
Villain, G., Baroghel-Bouny, V., Kounkou, C., Hua, C., 2001. Mesure de la perméabilité aux gaz en fonction du taux de saturation des bétons. Revue Française de Génie Civil 5, 251-268.

Wang, C.Y., Cheng, P., 1996. A multiphase mixture model for multiphase, multicomponent transport in capillary porous media. I. Model development. Int. J. Heat Mass Transfer 39, 3607-3618.

Yurtdas, I., Burlion, N., Skoczylas, F., 2004. Triaxial mechanical behaviour of mortar: effect of drying. Cement Concrete Res. 34, 1131-1143. 